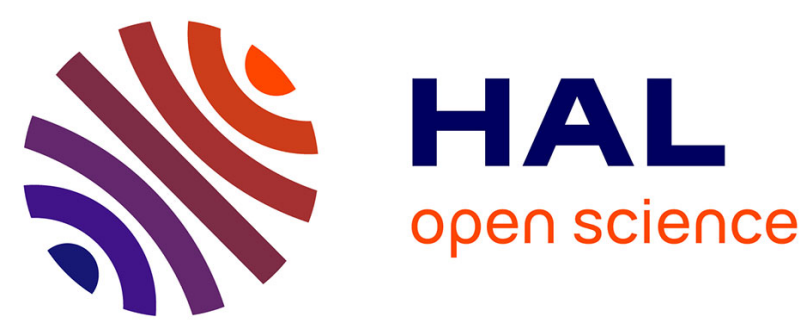

\title{
Stochastic evaluation of annual micropollutant loads and their uncertainties in separate storm sewers
}

Ali Hannouche, Ghassan Chebbo, Claude Joannis, Johnny Gasperi, Marie-Christine Gromaire, Régis Moilleron, Sylvie Barraud, Véronique Ruban

\section{- To cite this version:}

Ali Hannouche, Ghassan Chebbo, Claude Joannis, Johnny Gasperi, Marie-Christine Gromaire, et al.. Stochastic evaluation of annual micropollutant loads and their uncertainties in separate storm sewers. Environmental Science and Pollution Research, 2017, 24 (36), pp.28205 - 28219. hal-01883198

\section{HAL Id: hal-01883198 \\ https://hal-enpc.archives-ouvertes.fr/hal-01883198}

Submitted on 31 Mar 2020

HAL is a multi-disciplinary open access archive for the deposit and dissemination of scientific research documents, whether they are published or not. The documents may come from teaching and research institutions in France or abroad, or from public or private research centers.
L'archive ouverte pluridisciplinaire HAL, est destinée au dépôt et à la diffusion de documents scientifiques de niveau recherche, publiés ou non, émanant des établissements d'enseignement et de recherche français ou étrangers, des laboratoires publics ou privés. 


\title{
1 Stochastic evaluation of annual micropollutant loads and 2 their uncertainties in separate storm sewers
}

\author{
Hannouche, A. ${ }^{1,{ }^{*}}$; Chebbo, G. ${ }^{1,2}$, Joannis, C. ${ }^{3}$, Gasperi J. ${ }^{1}$; Gromaire M.C. ${ }^{1}$, Moilleron \\ R. ${ }^{(1)}$, Barraud S. ${ }^{3}$, Ruban V. ${ }^{3}$ \\ ${ }^{1}$ Université Paris-Est, LEESU (UMR-MA-102), UPEC, UPEMLV, ENPC, Agro ParisTech, 6 et 8 avenue \\ Blaise Pascal - Cité Descartes, 77455 Champs-sur-Marne Cedex 2, France \\ ${ }^{2}$ Faculty of Engineering III, Lebanese University, Hadath - Lebanon \\ ${ }^{3}$ LUNAM, IFSTTAR - LEE, Département Géotechnique Eau, Risques naturels et Sciences de la terre - \\ Laboratoire Eau et Environnement- route de Bouaye CS4 - 44344 Bouguenais cedex \\ ${ }^{4}$ Université de Lyon, INSA Lyon, Université Lyon1, DEEP, 34 avenue des Arts, 69621 Villeurbanne \\ cedex, France \\ Corresponding author: * ali.hannouche@ leesu.enpc.fr; +33(0) 1.64.15.39.50; +33(0) 1.64.15.37.64
}

\begin{abstract}
:
This article describes a stochastic method to calculate the annual pollutant loads and its application over several years at the outlet of three catchments drained by separate storm sewers. A stochastic methodology using Monte Carlo simulations is proposed for assessing annual pollutant load, as well as the associated uncertainties, from a few event sampling campaigns and/or continuous turbidity measurements (representative of the Total Suspended Solids concentration (TSS)). Indeed, in the latter case, the proposed method takes into account the correlation between pollutants and TSS. The developed method was applied to data acquired within the French research project "INOGEV" (Innovations for a sustainable management of urban water) at the outlet of three urban catchments drained by separate storm sewers. Ten or so event sampling campaigns for a large range of pollutants (46 pollutants and 2 conventional water quality parameters: TSS and total organic carbon (TOC)) are combined with hundreds of rainfall events for which, at least one among three continuously monitored parameters (rainfall intensity, flow rate and turbidity) is available.

Results obtained for the three catchments show that the annual pollutant loads can be estimated with uncertainties ranging from $10 \%$ to $60 \%$, and the added value of turbidity monitoring for lowering the uncertainty is demonstrated. A low inter-annual and inter-site variability of pollutant loads, for many of studied pollutants, is observed with respect to the estimated uncertainties, and can be explained mainly by annual precipitation.
\end{abstract}

Keywords: Stormwater; database; pollutant; annual load; turbidity; TSS; uncertainties; variability. 
38 In the case of separate storm sewers, runoff is usually discharged directly into the natural environment without any treatment. These discharges constitute a continuous and significant Weiss et al. 2008, Zgheib et al. 2012). The reduction of these discharges is a major issue of the EU Water Framework Directive (WFD) (2013/39/EU) to achieve the "good ecological status" for all of Europe's surface waters and groundwater. This challenge requires accurate knowledge of pollutant loads discharged by separate sewer. Beyond the conventional water quality parameters (Total Suspended Solids (TSS); Chemical Oxygen Demand (COD); etc.) extensively studied over several decades, monitoring of priority and/or emerging substances has become an important issue in Europe to meet the requirements of the WFD (Sebastian et al. 2011). Due to financial costs, operational and technical issues, the assessment of pollutant loads is constrained by a lack of suitable measuring devices. Monitoring is frequently carried out by taking samples for subsequent analysis in the laboratory. Analytical methods are standardized but still pollutant dependant. Yet, the sampling process has some major drawbacks, among which the limited number of samples which can practically be handled due to random occurrence of rain events, frequent maintenance, etc. Indeed, monitoring programs prove to be very costly and require considerable staff time. Only a limited number of campaigns (generally less than 5) are thus carried out during a given year (Gromaire et al. 2007) for operational purposes, and data are usually pooled to derive an Annual (or Sitespecific) discharge-weighted (or arithmetic) Mean Concentration SMC, whose value is then multiplied by the total runoff volume of the considered period to assess pollutant loads. This method induces large uncertainty values (Mourad et al. 2005).

Besides these considerations TSS have been revealed as the predominant pollutant vector in sewer systems (Ashley et al. 2005, Zgheib et al. 2012). In fact, for some pollutants such as PAH, PCB and metals, TSS is a significant vector, while isn't for other pollutants such as Octylphenol OP, TSS is not the significant vector (Zgheib et al. 2012).

Continuous turbidity measurements can now provide recordings which are representative of the TSS concentration. Actually, turbidity can be translated into TSS concentration by using an average TSS-Turbidity relationship at different time-scales (Hannouche et al. 2011, Lacour et al. 2009, Langeveld et al. 2005, Metadier and Bertrand-Krajewski 2012). TSS concentration time-series are thus made available. The use of continuous measurement data (rain intensity, flow rate, turbidity), in addition to a limited number of laboratory analysis by sampling, therefore enables a more accurate assessment of the annual micropollutants flux.

In this context, the "INOGEV" project (Innovations for a sustainable management of urban water) was launched in early 2010 by the national network of French observatories in urban hydrology "SOERE URBIS" (A long-term Observation System for research and Experimentation on urban environment) combining the works of "OPUR" in Paris (Observatory of Urban Pollutants in Île-de-France/Paris region, since 1994), "OTHU" in Lyon (Field Observatory for Urban Water Management in Lyon-France, since 1999) and "ONEVU" in Nantes (Observatory of urban environments of Nantes- France, since 2006). This project aimed at improving the knowledge and control of the contamination of urban stormwater in a multidisciplinary approach as regards scientific research, operational practices and social understanding. By harmonizing scientific approaches and monitoring methodologies (pollutants, sampling, analytical methods and results interpretation) at the scale of three urban districts featuring distinct land use patterns and contexts, a new extended 
French dataset has been built for a large range of pollutants at the event scale (Gasperi et al. 2014). In addition, the observatories had formerly provided some statistically representative databases for water flow rate and turbidity measurements for several years at the outlet of two of the three studied catchments.

In this paper, a combined approach was adopted coupling the new dataset of pollutant concentrations and available recordings of hydrological and water quality parameters (rainfall intensity, flow rate, turbidity), to assess annual pollutant loads as well as the associated uncertainties. First the databases used are briefly presented. Then, the methodology developed to assess the annual loads and their uncertainty for a given pollutant including the underlying hypotheses is described. Results obtained are then discussed and compared between the three sites.

\section{EXPERIMENTAL DATA}

\section{Sites description}

Three experimental sites drained by a separate sewer systems (Sucy in Île-De-France/Paris region, Chassieu in Lyon and Pin Sec in Nantes) were considered. Table 1 summarizes the main characteristics and the available databases at the three sites. Their areas range from 30 to 228 ha and their runoff coefficients (RC) vary between 22 (Sucy) to 30\% (Chassieu). Chassieu is an industrial catchment while other catchments are residential with mostly small private houses and limited commercial and professional activity (small shops and services) at Sucy catchment, and mainly collective buildings and private houses at Pin Sec catchment. On the whole, most of buildings and houses were built between the years1970 and 1980 .

Table 1: Sites and databases available

\begin{tabular}{|c|c|c|c|c|c|c|}
\hline Sites & Location & Area & $\mathrm{RC}^{1}$ & Land use & Slope & Available data \\
\hline Sucy & $\begin{array}{l}\text { Paris, } \\
\text { South- } \\
\text { East }\end{array}$ & 228 ha & 0.22 & Residential & $0.2 \%$ & 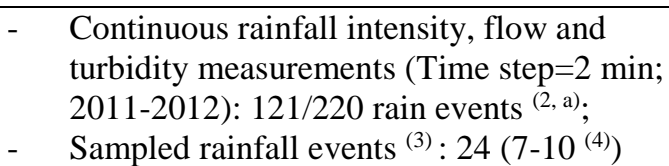 \\
\hline Chassieu & $\begin{array}{c}\text { Lyon, } \\
\text { East }\end{array}$ & 185 ha & 0.30 & Industrial & $0.4 \%$ & 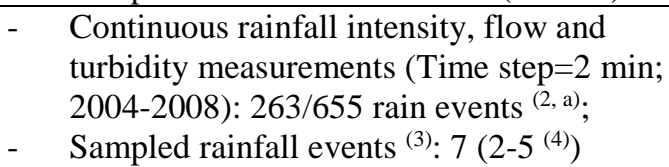 \\
\hline Pin Sec & $\begin{array}{l}\text { Nantes, } \\
\text { North- } \\
\text { East }\end{array}$ & 30 ha & 0.26 & $\begin{array}{l}\text { Residential } \\
\text { and } \\
\text { collective } \\
\text { housing }\end{array}$ & $1.0 \%$ & $\begin{array}{l}\text { - } \quad \text { Continuous rain intensity and flow } \\
\text { measurements (Time step=5 min; } 2011 \text { - } \\
\text { 2012): } 198 / 214 \text { rain events }(2, \mathrm{~b}) \\
\text { - } \\
\text { Sampled rainfall events (3): } 18 \text { (7-15 (4)) }\end{array}$ \\
\hline
\end{tabular}

(1) RC = runoff coefficient (see Precipitation - volume model (Model M1) for more information), (2) number of rainfall events with: (a), valid flow and turbidity measurements compared to all identified rain events, $(b)$ valid flow measurements compared to all identified rain events (no turbidity measurement at Pin Sec site); (3) Number of rainfall events sampled at each site with measurements of global parameters; (4) Number of rain events analyzed for each group of micropollutants.

\section{Available monitoring data}

\section{Sampled rainfall events and measured pollutants}

Depending on the site under consideration, between 7 and 24 rainfall events were sampled from July 2011 to May 2013 with automatic samplers controlled by a flow-meter to obtain flow proportional event mean concentrations (EMC). The sampling equipment and field blank procedures were harmonized between observatories and described in (Gasperi et al. 2014). 
The main characteristics of these events such as precipitation depth ( $\mathrm{H}$ in $\mathrm{mm})$, mean and max intensity in 5 min ( $\mathrm{I}_{\text {mean }}$ and $\mathrm{I}_{\max }$ in $m m \cdot h^{-1}$ ) and preceding dry weather period (PDWP in days) are given in Table 6 in supplementary materials section. On the whole, these rainfall events feature relatively low rainfall intensities, with no extreme rainfall amounts collected.

Conventional water quality parameters, such as TSS and total dissolved and particulate organic carbon (TOC, DOC and POC), were analyzed for each rain event sampled. A total of 46 micropollutants were monitored for 2 to 15 rainfall events, including 13 metals, 16 polycyclic aromatic hydrocarbons (PAH), 9 polybromodiphenylethers (PBDE), bisphenol A (BPA) and 7 alkylphenols (APnEOs). The full list of targeted molecules and the usual abbreviations are listed extensively in Table 7 supplementary materials section.

Turbidity data were processed and validated by using redundancy in Sucy (Lacour et al. 2009) site or by using the method detailed in (Mourad and Bertrand-Kralewski 2002) in Chassieu site.

Storm events are identified using flow rate and rainfall intensity. The beginning of the event is given by the rise of the flow rate signal whereas the end of the event is given by the return to the dry weather base-flow attributed to groundwater infiltration. In a second step, the runoff events identified are compared to rainfall data to eliminate all hydrographs which correspond to a precipitation depth lower than $0.5 \mathrm{~mm}$ (< Initial loss, see Precipitation - volume model (Model M1) for more information). During the years 2011 and 2012: i) 220 rain events have been identified for Sucy site including 121 rainfall events with valid flow and turbidity measurements, ii) and 214 rain events for Pin Sec site among which 198 events possess valid flow measurements). Over the period 2004-2008 in Chassieu site, the final validated database (flow and turbidity) contains 263 events among 655 identified rain events (Table 1). Indeed, data acquired at this site between 2011 and 2012 was not exploitable because of the failures of the peristaltic pump.

The main characteristics of these rainfall events are given in Table 2. The characteristics of these rainfall events are with the same magnitude as those sampled during the pollutant sampling campaigns. 
Table 2: Main rainfall characteristics of the identified rain events on the three study sites (d10-d50-d90).

\begin{tabular}{|c|ccccc|}
\hline & $\mathrm{H}(\mathrm{mm})^{(1)}$ & Duration $(\mathrm{h})$ & $\mathrm{I}_{\operatorname{mean}}\left(\mathrm{mm}^{-1}\right)$ & $\mathrm{I}_{\max }\left(\mathrm{mm}^{-1}\right)^{(2)}$ & PDWP $^{(3)}$ \\
\hline $\begin{array}{c}\text { Sucy } \\
(\mathrm{n}=121)\end{array}$ & $1.4-5.0-12.7$ & $1.0-4.7-13.0$ & $0.6-1.3-2.7$ & $2.4-4.8-21.6$ & $0.22-1.29-5.12$ \\
\hline $\begin{array}{c}\text { Chassieu } \\
(\mathrm{n}=263)\end{array}$ & $1.0-2.4-14.7$ & $0.7-3.5-13.0$ & $0.3-1.1-2.8$ & $1.5-4.4-17.5$ & $0.25-0.65-5.6$ \\
\hline $\begin{array}{c}\text { Pin Sec } \\
(\mathrm{n}=198)\end{array}$ & $1.3-3.2-13.0$ & $0.7-2.2-11.8$ & $0.8-2.2-3.6$ & $3.1-7.3-15.5$ & $0.11-0.97-9.54$ \\
\hline
\end{tabular}

1) Precipitation depth; 2) Imax evaluated over 5-min intervals; 3) Preceding dry weather period, in days.

\section{TSS-Turbidity correlation functions and uncertainties}

Previous research demonstrated that linear or polynomial function can be used to estimate TSS concentration from turbidity (Hannouche et al. 2011, Metadier and Bertrand-Krajewski 2012).

For Sucy, the discharge-weighted event mean turbidity (EMT) was calculated from the continuous and validated turbidity measurements for 14 rainfall events among the 24 rainfall events sampled in Sucy site. The 14 pairs (EMT, TSS) obtained allowed us to build the TSSturbidity linear function (Figure 1, $(a) ; T S S_{(m g / l)}=f\left(E M T_{(F A U)}\right)=31.9+0.45 E M T$, (Equation 1)) at the event scale. For each rainfall event $j$ for which there is a validated turbidity pollutograph $\left(T_{i j}\right)\left(i\right.$ is an index of the time step) and flow rate hydrograph $\left(Q_{i j}\right)$, a discharge-

weighted event mean turbidity is calculated $T_{j} \approx \frac{\sum_{i=1}^{n_{j}} T_{j i} \times Q_{j i} \times \Delta t_{j i}}{\sum_{i=1}^{n_{j}} Q_{j i} \times \Delta t_{j i}}$ (Equation 2) and then transformed into TSS event mass by applying the TSS-turbidity linear function established on this site. Finally, the residual error implied by this conversion is assessed by assuming that residual errors follow a normal distribution with same variance derived from residues observed for calibration data (Hannouche et al. 2011).

About sixty grab sample were taken in Chassieu site by (Metadier and Bertrand-Krajewski 2012) during wet weather conditions between 2002 and 2008 (we have no information on the number of sampled events). For each sample, 25 repeated turbidity measurements and triplicate TSS analysis according to usual standards methods are carried out, including assessment of uncertainties. These have allowed to build a second degree polynomial function $\left(T S S_{(m g / l)}=12.9+0.7 * T_{(F N U)}+7.8 \mathrm{e}-4 * T^{2}{ }_{(F N U)}\right.$, (Equation 3)) by means of Williamson weighted least squares regression method accounting for uncertainties in both coordinates (TSS and turbidity) A detailed description of this method and uncertainty estimation are reported in (Metadier and Bertrand-Krajewski 2011). The obtained correlation function in Chassieu is given in Figure 1, (b).

Note that the difference in procedure for estimation of TSS concentration at both sites is due to the methods of turbidity measurements and to available TSS-Turbidity data on each site. 

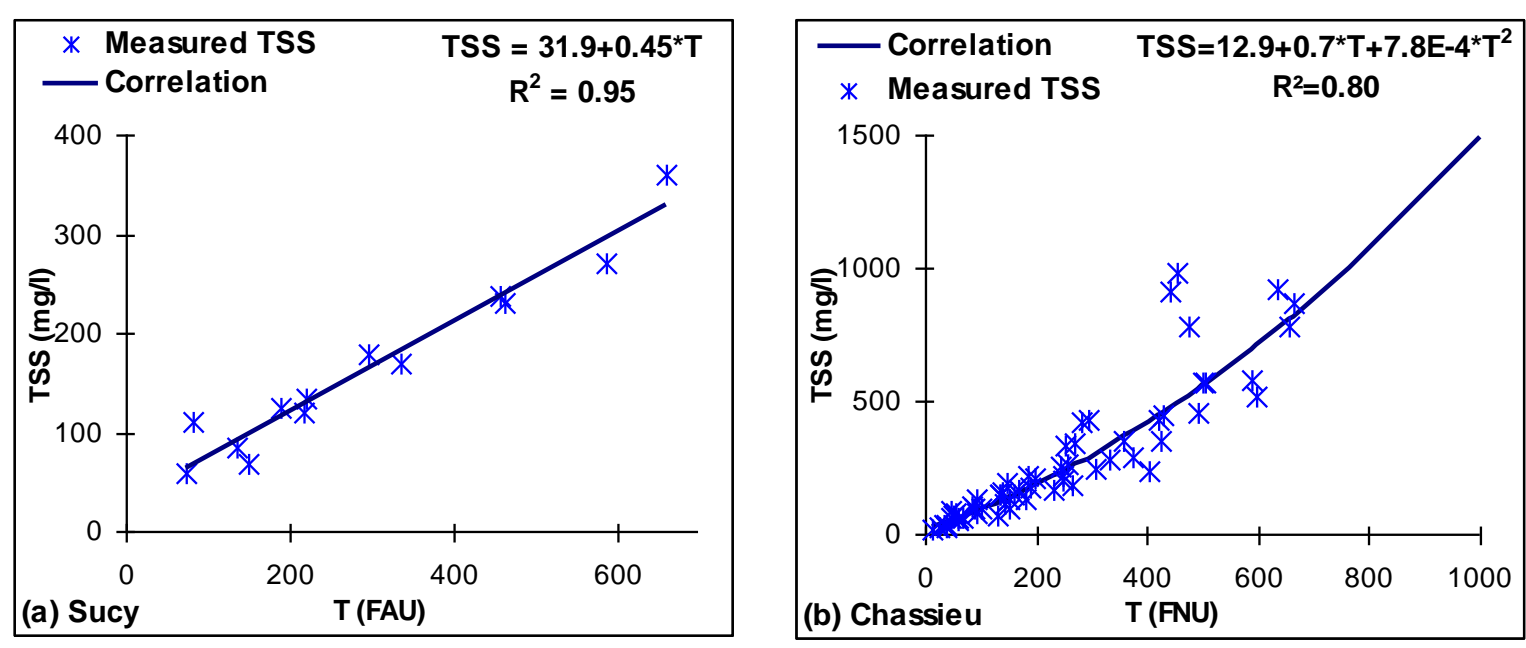

Figure 1: TSS-Turbidity correlation functions: (a) Sucy ; (b) Chassieu

The two correlation functions on both sites are different. This may be mainly due to measuring and calculation methods used at each site (attenuation in Sucy and nephelometry in Chassieu). Indeed, at the Chassieu site, this relationship was established by (Metadier and Bertrand-Krajewski 2011) for instantaneous samples with turbidity measured in nephelometry. While on the Sucy site, we calculated event mean turbidity for rain events (which are less variable than those of instantaneous turbidities), for which the event mean concentration and turbidity pollutograph are known. Moreover, although the y-intercept (measurement offset) at Sucy site is quite high $(31.9 \mathrm{mg} / \mathrm{l}$ TSS at $0 \mathrm{FAU})$, its variability at $95 \%$ prediction intervals is approximately $\pm 25 \mathrm{mg} / \mathrm{l} \mathrm{TSS}$. It should be noted that this relationship was established for a range of turbidity between 70 and 660 FAU and was used for turbidities varying between 60 and $700 \mathrm{FAU}$ (average value $=250 \mathrm{FAU}$ ).

\section{CALCULATION METHOD}

In the case of a discrete sampling of all events for a given year, the pollutant loads $M_{p o l}$ for year $k$ could be calculated by sequential summation of loads $M_{j_{p o l}}$ of all rainfall events (indexed by $j$ with a number $N_{\text {events }}$ ) that occurred during this year and by sequential summation at time step $i$ (with a number $n_{j}$ time step), over the duration of each event. It is further assumed that the pollutant load transited during dry weather periods (improper connections, infiltration...) is negligible compared with the one transported during wet weather periods throughout one year. So:

$M_{p o l}=\sum_{j=1}^{N_{\text {events }}} M_{p o l \mathrm{j}} \approx \sum_{j=1}^{N_{\text {events }}} \sum_{i=1}^{n_{j}} C_{T-p o l} \times Q_{j i} \times \Delta t_{j i}$ (Equation 4)

With $Q_{j i}=$ flow rate and $C_{T-p o l}=$ total (i.e. dissolved and particulate) pollutant concentration at time step $i\left(\Delta t_{j i}\right)$ during the event $j$. The symbol $(\approx)$ indicates that there is a discretization error.

Thus, estimating the mass $M_{j_{p o l}}$ using the above formula requires knowledge of the dynamics of total pollutant concentration $C_{T-p o l}$ and flow rate at each time step. Actually, the details of the dynamics of pollutant loads within a rainfall event is not considered by itself, but only as a mean to get an integrated value of the product $\mathrm{Q}_{\mathrm{ji}} \times C_{T-p o l_{j i}} \times \Delta t_{j i}$ over the 
duration of the rainfall event. Thus an analysis performed on a flow-weighted composite sample representative of the entire rainfall event $j$ is sufficient for estimating the total pollutant EMC $C_{T-p o l_{j}}$, and assessing the event load $M_{j_{p o l}}$ of rainfall event $j$ as $M_{j_{p o l}}=C_{T-p_{0} l_{j}} \times V_{j}$ (Equation 5) with $V_{j}$ is the volume of water transported during the rainfall $j$.

Continuous monitoring of flow rate is commonly available, and the equation 5 can be applied to events for which monitoring was carried out for providing $C_{T-p o l_{j}}$. But pollutant concentrations data are always very scarce, due to sampling and analysis constraints. So we investigate the possible combination of continuous monitoring of some parameters with analyses performed on flow rate averaged event mean samples collected from a few rain events. We especially focus on the added value of turbidity monitoring for improving the assessment of pollutant annual load for pollutants which are significantly correlated with TSS EMC.

In this scope, we distinguish two types of pollutants according to the dependence of their total concentrations on TSS concentration. Indeed, the total pollutant concentration $C_{T-p o l}$ is expressed as the sum of dissolved $C_{D-p o l}($ unit $/ l)$ and particulate $C_{P-p o l}($ unit/l) concentrations (unit $\sim m g$ or $\mu g$ or $n g$ ):

$C_{T-p o l}=C_{D-p o l}+C_{P-p o l}=C_{D-p o l}+\tau \times T S S$ (Equation 6), with TSS(mg/l) is TSS EMC concentration and $\tau$ is the particle pollutant content (unit/mg TSS, i.e. $\tau=$ particulate concentration $/$ TSS concentration $\left.=C_{P-p o l} / T S S\right)$.

The combination of pollutograph and hydrograph of a rainfall event $j$ allows us to estimate the TSS EMC of this rainfall event using (equations 1, 2 and 3).

After identifying the rainfall events in a given year (using precipitation and flow rate time series), from one to four stochastic models are used to handle missing data and finally get an assessment of total pollutant EMC for a given pollutant for any event. Then, an annual flow weighted concentration is derived from the EMC values for all events in one particular year, and the process is repeated by the means of Monte-Carlo simulation to derive a mean value and a confidence interval for each considered pollutant.

\section{Model structures}

For a given event, two models are used to handle the lack of continuously monitored data:

1. A precipitation - volume model (model M1) to estimate a value and its uncertainty of the runoff volume of a rainfall event for which there is no flow rate measurement.

2. A TSS EMC model (model M2) to estimate the TSS EMC probability distribution of a rainfall event for which neither TSS EMC analysis nor turbidity measurements were available (either due to the lack of sensor or to a drift or failure of available sensors).

In addition, two other models are used to extrapolate data from the few events sampled for pollutant EMC analysis to other events, where such analysis is missing:

3. M3 is used when no correlation between $C_{P-p o l}$ EMC and TSS EMC is identified, and $C_{T-p o l}$ EMC.

4. M4 is used when a significant correlation between $C_{P-p o l}$ EMC and TSS EMC is identified and provides the probability distribution of $C_{T-p o l}$ EMC as the sum of $C_{D-p o l}$ 
EMC overall probability distribution and $C_{P-p o l}$ EMC probability distribution assessed from TSS EMC value and $\tau$.

\section{Precipitation - volume model (Model M1)}

The first model (M1) is a linear model using the runoff coefficient $R C$ to estimate the event volume $V$ as a function of the precipitation $H$ according to the relationship $V=10 \times A \times R C \times(H-I L)$ where $I L$ is the initial loss (in $\mathrm{mm}$ ) and $A$ is the catchment surface area (in ha). For a given catchment, model M1 was fitted by means of least squares method using all the events for which simultaneous flow rate and rainfall intensity are available. Figure 2 illustrates the runoff model $(V=10 \times A \times R C \times(H-I L))$ (Equation 7) obtained on each site and the corresponding $95 \%$ prediction intervals (95\% PI). The obtained runoff coefficients $R C$ are reported in Table 1 above.
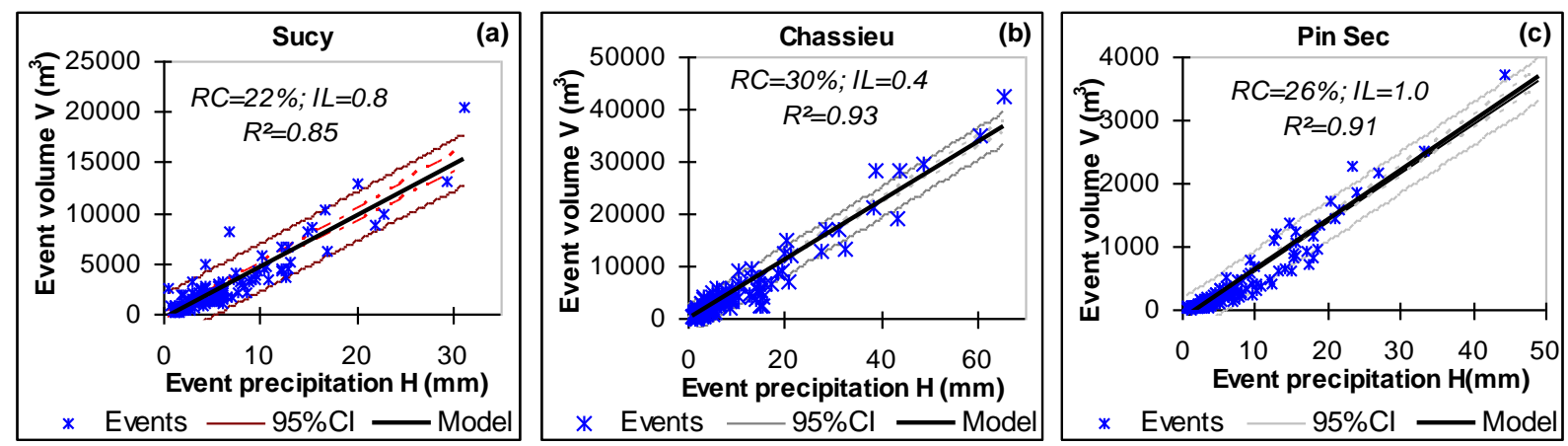

Figure 2: Runoff models and corresponding $95 \% \mathrm{CI}$ ( $\mathrm{RC}=$ runoff coefficient, IL = initial loss) for: (a) Sucy, (b) Chassieu and (c) Pin Sec

296

297

298

299

300

301

302

303

304

\section{TSS EMC model (Model M2)}

No model could be identified for linking the TSS EMC for a rainfall event to the characteristics of this event (precipitation depth, rainfall intensity, preceding dry weather). A probability distribution model (M2) was used instead and fitted to all TSS measures available on a given site or derived from turbidity measurements. For a given site, the KolmogorovSmirnov test was used to fit theoretical and TSS EMC empirical distributions at the 5\% level. Different simulations show that the lognormal distribution is well suited for describing the TSS EMC (KS test, $\alpha=5 \%$ ). Hence, both the mean $(m)$ and standard deviation $(S D)$ of EMCs (estimated distribution) have been calculated first in natural logarithm space ( $\mu$ and $\sigma$ mean and standard deviation of $(\ln (T S S E M C))$ and then transformed into arithmetic space (Romeu 2002) using the formulas: $m=\exp \left(u+\sigma^{2} / 2\right)$ and $S D=\sqrt{\exp \left(\sigma^{2}\right)-1} \times m$ (Equations $8 \& 9$ ) where $\exp (x)$ is the exponential function of $x$. The parameters of fitted distributions for different sites are summarized in Table 3.

Table 3: Means and SD of the fitted lognormal distributions of TSS EMC and those of $\boldsymbol{n}$ rainfall events on the three sites Sucy, Chassieu and Pin Sec

\begin{tabular}{|c|c|c|c|c|c|c|c|c|}
\hline Site & $\mathrm{n}$ & $\mu$ & $\sigma$ & $\mathrm{m}$ & $\mathrm{SD}$ & KS p-value $^{(1)}$ & $\overline{E M C}^{(2)}$ & $\sigma_{E M C}{ }^{(2)}$ \\
\hline Sucy & 121 & 4.83 & 0.49 & 141 & 74 & $84 \%$ & 141 & 73 \\
\hline Chassieu & 263 & 4.63 & 0.79 & 140 & 130 & $87 \%$ & 144 & 144 \\
\hline
\end{tabular}




\begin{tabular}{|c|c|c|c|c|c|c|c|c|}
\hline Pin Sec & 18 & 4.57 & 0.76 & 128 & 114 & $82 \%$ & 124 & 85 \\
\hline
\end{tabular}

Note that the TSS EMCs on both Sucy and Chassieu sites were calculated from the turbidity data, while those of Pin Sec site are those of the measurement campaigns (Table 6). KruskalWallis statistical test shows that the distributions of TSS EMCs are not significantly different between the three sites $(\alpha=5 \%$ and $p$-value=17\%). In addition, the same test shows that there is no significant difference between the distribution of TSS EMC from one year to another in the same site (Sucy and Chassieu sites).

\section{$\mathrm{C}_{\mathrm{T}-\mathrm{pol}}$ EMC models (Models M3 and M4)}

As for TSS, no model was identified for assessing the total pollutant EMC $\mathrm{C}_{\mathrm{T} \text {-pol }}$ according to the characteristics of the corresponding rainfall event. So, a distribution model was applied. Figure 3 illustrates the methodology of calibration of the distribution model of $C_{T-p o l}$ EMC.

First of all, the significance of the correlation coefficient $\left(\rho_{\text {TSS-pol part }}\right)$ between TSS EMC and particulate concentration $C_{P-p o l}$ EMC was tested for a given pollutant by using Pearson parametric test for normal distribution or Spearman nonparametric test otherwise $(\alpha=5 \%$ for all these tests). The significance of this correlation leads the choice between two models:

1. No significant correlation: a distribution of $C_{t-p o l}$ EMC (in $\mu g / l$ ) (model M3) is used. Model distributions are then fitted, using KS test $(\alpha=5 \%)$ when the number of events is greater than or equal to 6 (Romeu 2003);

2. Significant correlation: a model (model M4) is used, which results from a distribution of contents $\tau$ (e.g. $\mu g / m g$ TSS), a value of TSS EMC (e.g. $m g / l$ ) (obtained by turbidity measurements or M2 model) and a distribution of dissolved concentrations $C_{D \text {-pol }}$ EMC (e.g. $\mu g / l)$. The distributions of $\tau$ and of $C_{D-p o l}$ EMC are fitted if the number of events is $\geq 6$. Then, we calculate the total EMC $C_{t-p o l}$.

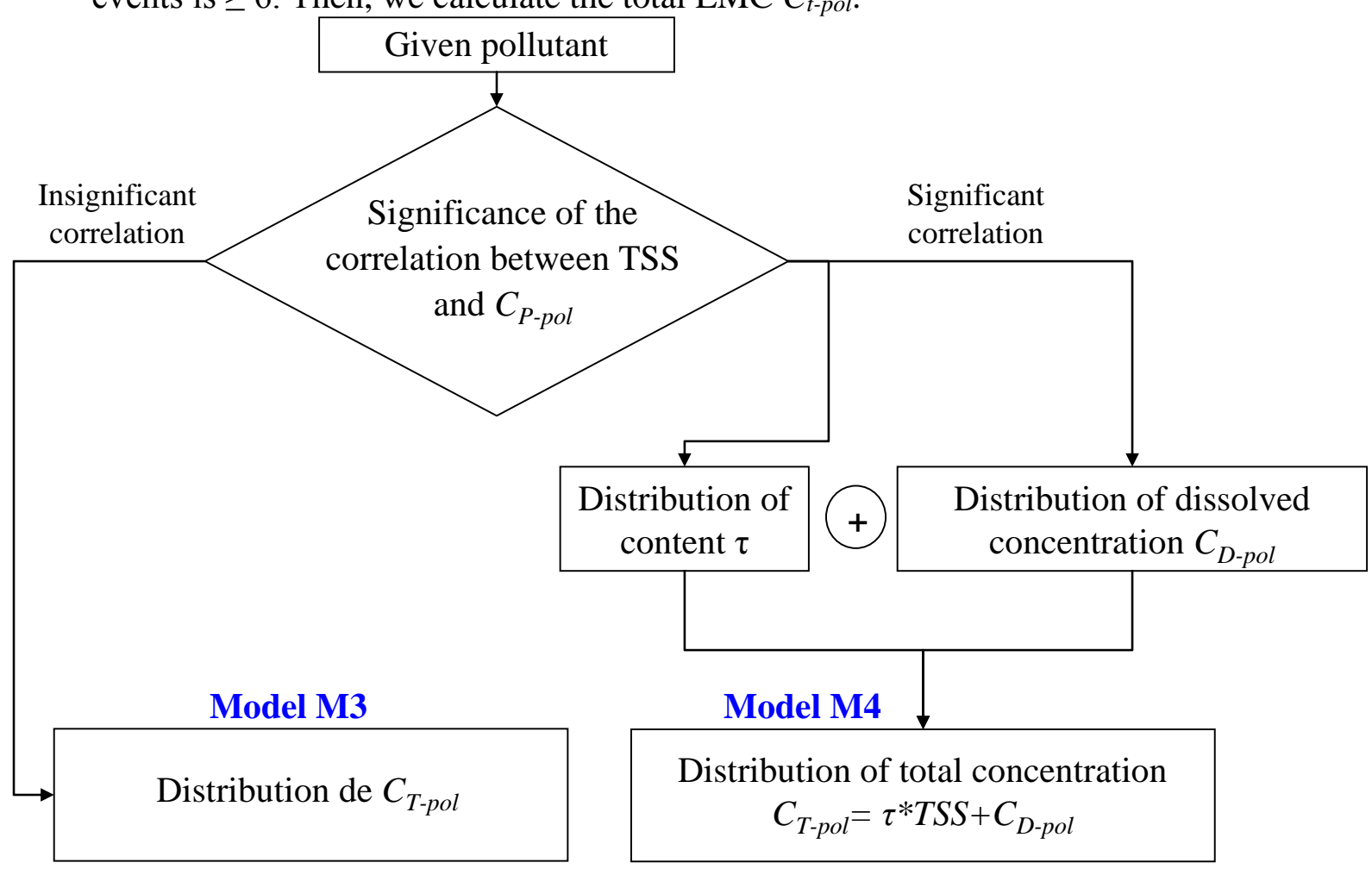


Furthermore, the rather low number of sampled rainfall events (Table 1) is not practical to fit a distribution of EMC for a given pollutant and a given site, especially in the case of Chassieu site (2 to 5 measurements per pollutant, Table 1). To solve this problem, the data from all three sites were pooled when no significant site-to-site difference between the EMC distributions of this pollutant was detected. Indeed, the homogeneity of $C_{T-p o l} E M C$ for model M3 (or $C_{D \text {-pol }}$ EMC or $\tau$ for model M4) for a given pollutant between three sites is verified at the level of 5\% (ANOVA parametric test if the homogeneity of variance (Levene's test) and normality (Shapiro-Wilk normality test) are accepted, Kruskal-Wallis non-parametric test otherwise (often used as an alternative to the ANOVA where the assumption of normality is not acceptable)). In the case of rejection of the hypothesis of homogeneity of $C_{T-p o l}\left(C_{D-p o l}\right.$ EMC or $\tau$ ), the Siegel-Tukey test of multiple comparisons is applied to find homogeneous groups of sites for a given pollutant. All these statistical tests were performed with the statistical software XLSTAT ${ }^{\circledR} \quad$ (version 2009.3.02, Addinsoft, New York, http://www.xlstat.com).

Kolmogorov-Smirnov test shows that lognormal distributions are well suited to describe pollutants EMCs at the level of 5\%: total $C_{T-p o l}$, dissolved $C_{d-p o l}$ and particle contents $\tau$ (KS pvalue $\geq 20 \%$ ). These results are in good agreement with those observed in the literature (EPA 2005, Francey et al. 2010, Mourad et al. 2005, Smullen et al. 1999).

$C_{T-p o l}$ EMC for the different pollutants and groups of pollutants were hence estimated. Indeed, the results for each metal are presented. By contrast, PAHs are presented on the basis of total concentrations, i.e. $\sum_{16} P A H$ (EPA 2005) or $\sum_{13} P A H$ (excluding volatile PAH: N, Acen and Acyl). For PBDE, the results are presented for ${ }_{9} P B D E$ and deca-BDE (BDE-209) which displayed the highest concentrations compared to other PBDE. The results of BPA, of octylphenols ( $\Sigma \mathrm{OP}$, octylphenol and octylphenol ethoxylates) and nonylphenols ( $\sum \mathrm{NP}$, nonylphenol and nonylphenol ethoxylates) are also presented.

Figure 4 and Erreur! Source du renvoi introuvable. illustrate in the approach applied for two pollutants: $\sum \mathrm{OP}$ and $\mathrm{Pb}$. The method presented above is discussed in both figures.

Parameters of the different distributions for models M3 and M4 in natural logarithm space $(\mu$ and $\sigma$ ) are reported in Table 8 in supplementary materials. For more details about the intra and inter-site variability of concentration for a given pollutant, an analysis with a comparison with literature, is detailed in (Gasperi et al. 2014). 

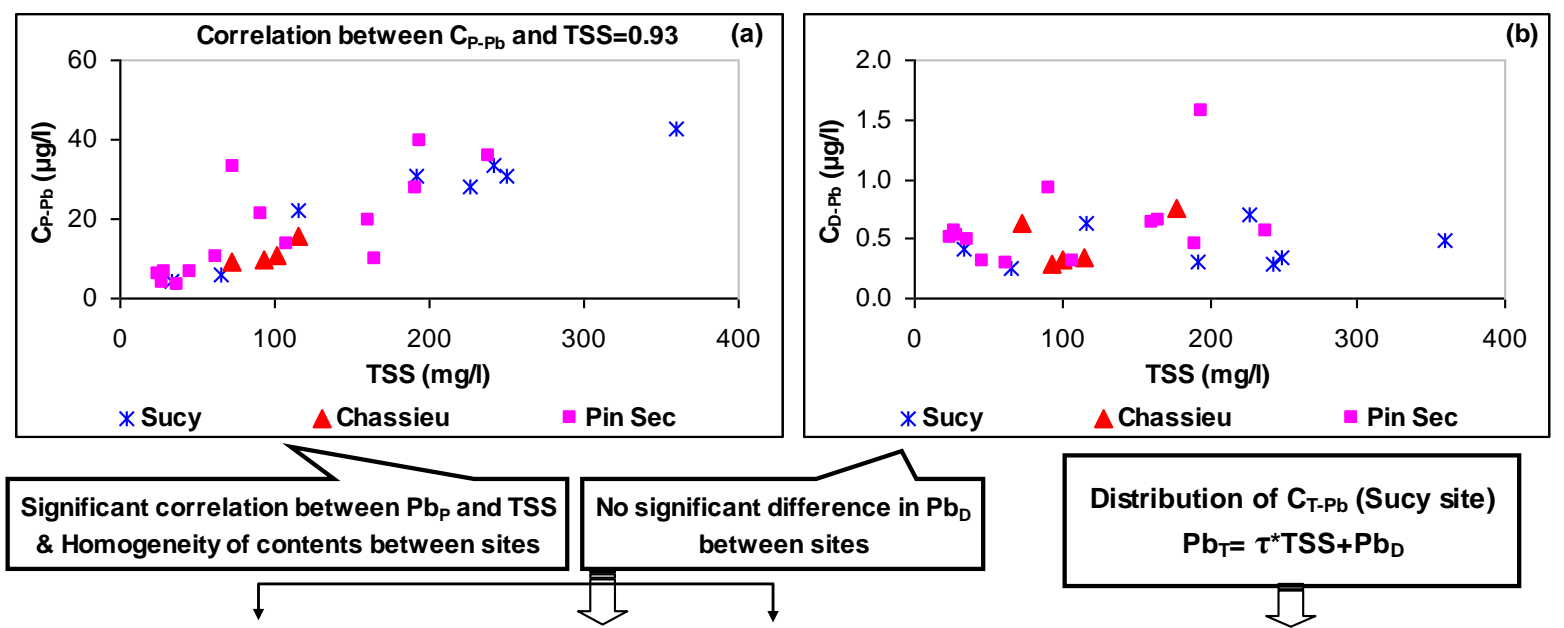

Distribution of $\mathrm{C}_{\mathrm{T}-\mathrm{Pb}}$ (Sucy site)

$\mathrm{Pb}_{\mathrm{T}}=\tau^{\star} \mathrm{TSS}+\mathrm{Pb}_{\mathrm{D}}$
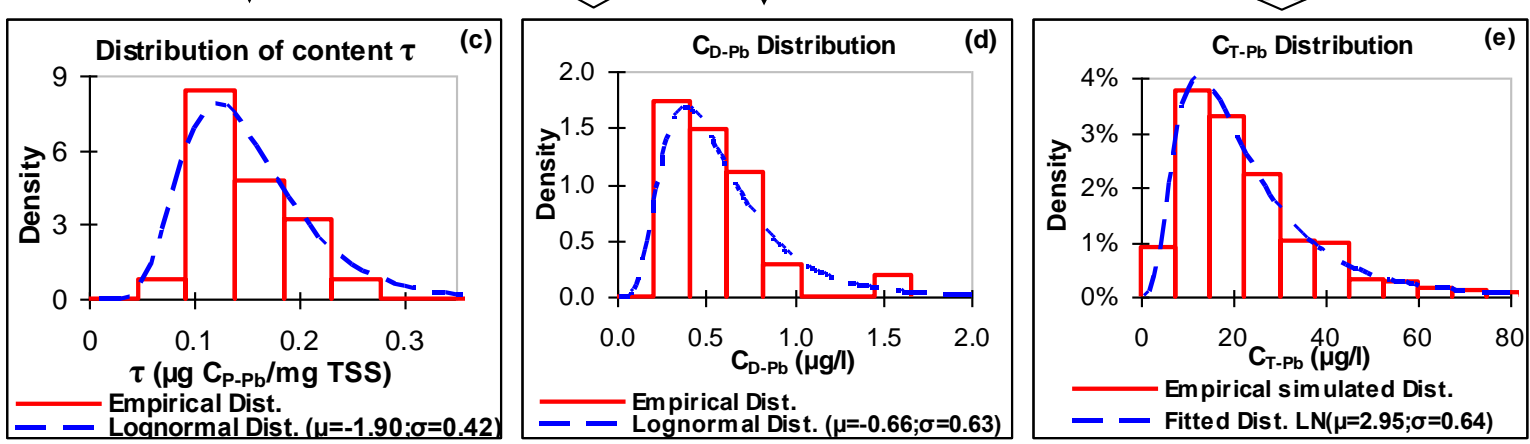

Figure 4: Example of the construction of the model of CT-Pol EMC (M4) for Pb; (e): case of Sucy site
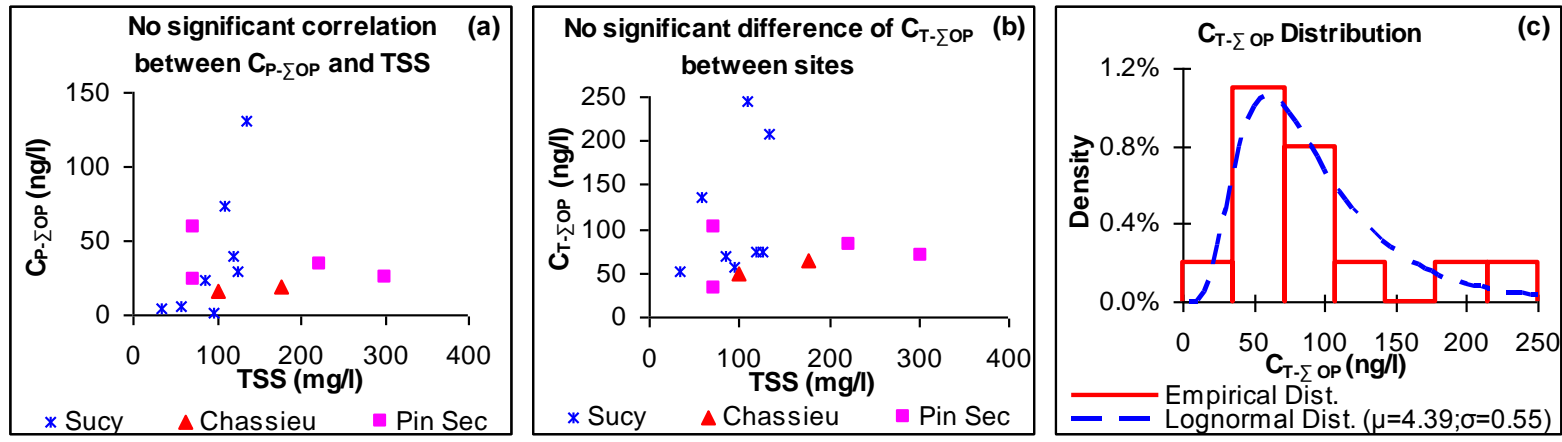

Figure 5: Example of the construction of the model of $\mathrm{C}_{\mathrm{T} \text {-Pol }} \mathrm{EMC}$ (M3) for $\sum \mathrm{OP}$

When validated, the lognormal distribution obtained by model M3 is directly used in the calculation of the annual load of this pollutant (example Erreur! Source du renvoi introuvable. $c)$ ).

Alternatively, two independent simulations (condition of independence has been checked using the partition coefficient $\left.\mathrm{K}_{\mathrm{d}}=\tau / C_{D-p o l}\right)$ using obtained lognormal distributions of $\tau$ (Figure $4(c))$ and total $C_{D-p o l}($ Figure $4(d)$ ) for a given pollutant are coupled with a TSS concentration (calculated using turbidity or simulated using model M2) to calculate a $C_{T-p o l}$ of this pollutant for the corresponding event (Figure $4(e)$ ).

\section{Monte Carlo simulations}

Monte Carlo simulations are used to combine the different models detailed above for each particular event in a given year and propagate the probability distributions from each model involved for each event to the annual average values and quantify the associated uncertainties. Figure 6 illustrates the methodology for assessing pollutant annual load $M_{P o l}$ for a given year and for a given pollutant using a Monte Carlo simulation (ISO/IEC 2008). Note that the 
hypothesis of independence between the event volume and concentration was checked for sampled events.

Then, the masses of all the events of this year for a given pollutant are summed up. This process was then reiterated 10,000 times for each year to obtain a probability distribution of annual load $M_{P o l}$. The average pollutant annual load and the corresponding uncertainties are derived from load distribution by using a 95\% confidence interval (shortest $95 \%$ confidence interval as recommended by (ISO/IEC 2008) standard).

In addition to sources of variability in the models $M 2$ to $M 4$, various sources of uncertainties are taken into account in the simulation such as:

- Measurement uncertainties: the uncertainties in the measured value are assumed to be normally distributed and independents with their standard uncertainty for:

○ Laboratory analyses: a relative standard deviation (\%RSD) equal to $15 \%$ (Gromaire and Chebbo 2001, Ruban et al. 2010);

○ Precipitation depth $H_{j}$ : a $\%$ RSD equal to $10 \%$;

- Flow rate $Q_{\mathrm{ij}}$ : a $\%$ RSD equal to $10 \%$;

- Turbidity: a value of 10 FAU or 10 FNU was used as standard uncertainty (Lacour et al. 2009, Metadier and Bertrand-Krajewski 2012).

- Prediction errors of the event volume (Model M1): this one was taken into account using residual errors implied by the linear model established at a given site. Residual errors are homoscedastic and normally distributed;

- Prediction errors of Turbidity-TSS correlation function $f(T)$.

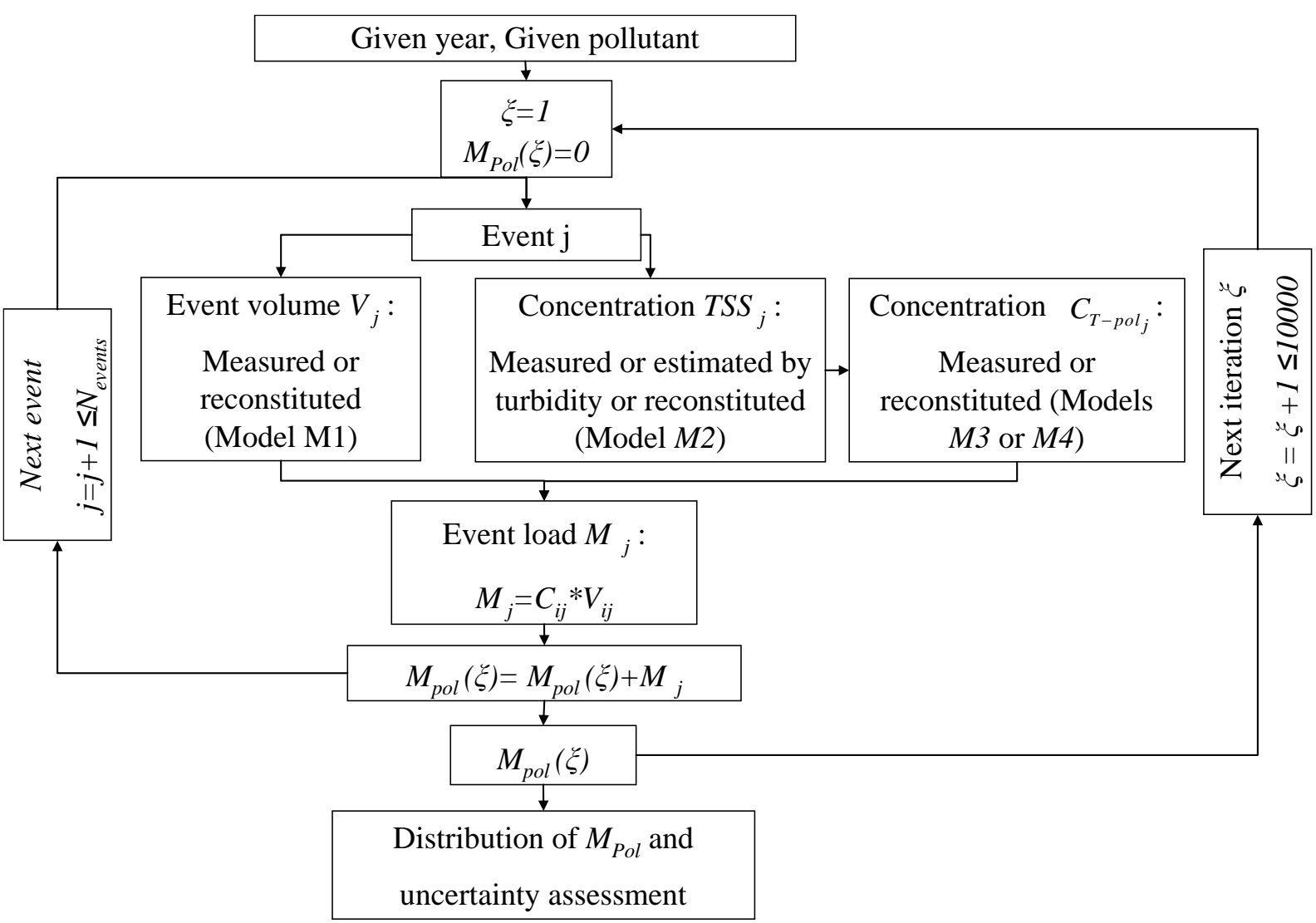
(http://www.scilab.org). In the following section, results for TSS and TOC annual loads and those obtained for the different pollutants are discussed. The calculation was performed for 2 
years in Sucy and Pin Sec sites (2011 and 2012) and for 5 years in Chassieu site (2004 to 2008). To compare the results between the three sites, annual loads for each site are normalized by active area (act.ha) and they will be called specific annual loads. The active area $S_{a c t}$ of a catchment is the area that really contributed to runoff. It was determined by the area $A$ of each catchment and the average runoff coefficient $R C$ obtained using model M1 ( $S_{a c t}$ $=R C$. Area, see Table 1 and Figure 2). Sact is about 50 ha in Sucy, 55 ha in Chassieu and 8 ha in Pin Sec.

\section{APPLICATION ON THE THREE SITES}

\section{Annual precipitations and volumes}

At the annual scale, the volumes ( net annual precipitation $\left.\mathrm{H}_{\mathrm{n}}=\left(\sum_{\mathrm{j}} \mathrm{H}_{\mathrm{j}}-\mathrm{IL}\right)\right)$ expressed in $\mathrm{mm}$ $\left(\sim 10 \mathrm{~m}^{3} /\right.$ act.ha) are shown in Table 4. The Chassieu site has an annual rainfall greater than that precipitated in Sucy and Pin Sec sites, which will affect the annual volumes.

Table 4 : Annual volumes on the three studied sites ( $\pm 95 \%$ empirical confidence intervals)

\begin{tabular}{|c|c|c|}
\hline \multirow{2}{*}{ Site } & Year & $\begin{array}{c}\text { Annual volume } V y / S_{\text {act }} \\
\left(\mathrm{mm}=10 \mathrm{~m}^{3} / \text { act.ha }\right)\end{array}$ \\
\hline \multirow{3}{*}{ Sucy } & 2011 & $440 \pm 10$ \\
\cline { 2 - 3 } & 2012 & $525 \pm 10$ \\
\hline \multirow{5}{*}{ Chassieu } & 2004 & $810 \pm 15$ \\
\cline { 2 - 3 } & 2005 & $580 \pm 15$ \\
\cline { 2 - 3 } & 2006 & $690 \pm 10$ \\
\cline { 2 - 3 } & 2007 & $775 \pm 10$ \\
\cline { 2 - 3 } & 2008 & $840 \pm 10$ \\
\hline \multirow{2}{*}{ Pin Sec } & 2011 & $515 \pm 10$ \\
\cline { 2 - 3 } & 2012 & $530 \pm 10$ \\
\hline
\end{tabular}

\section{TSS and TOC annual loads}

436 Specific annual loads of TSS and TOC, for 2 years in Sucy and Pin Sec sites and for 5 years in 437 Chassieu site are illustrated in Figure $7(a, b)$.

438 The average values of TSS specific load in Sucy and Pin Sec sites (between 550 and 700 $439 \mathrm{~kg} / \mathrm{act} . \mathrm{ha} / \mathrm{year}$ ) are lower than those of the Chassieu site (between 700 and 1100 $440 \mathrm{~kg} / \mathrm{act} . \mathrm{ha} /$ year). 

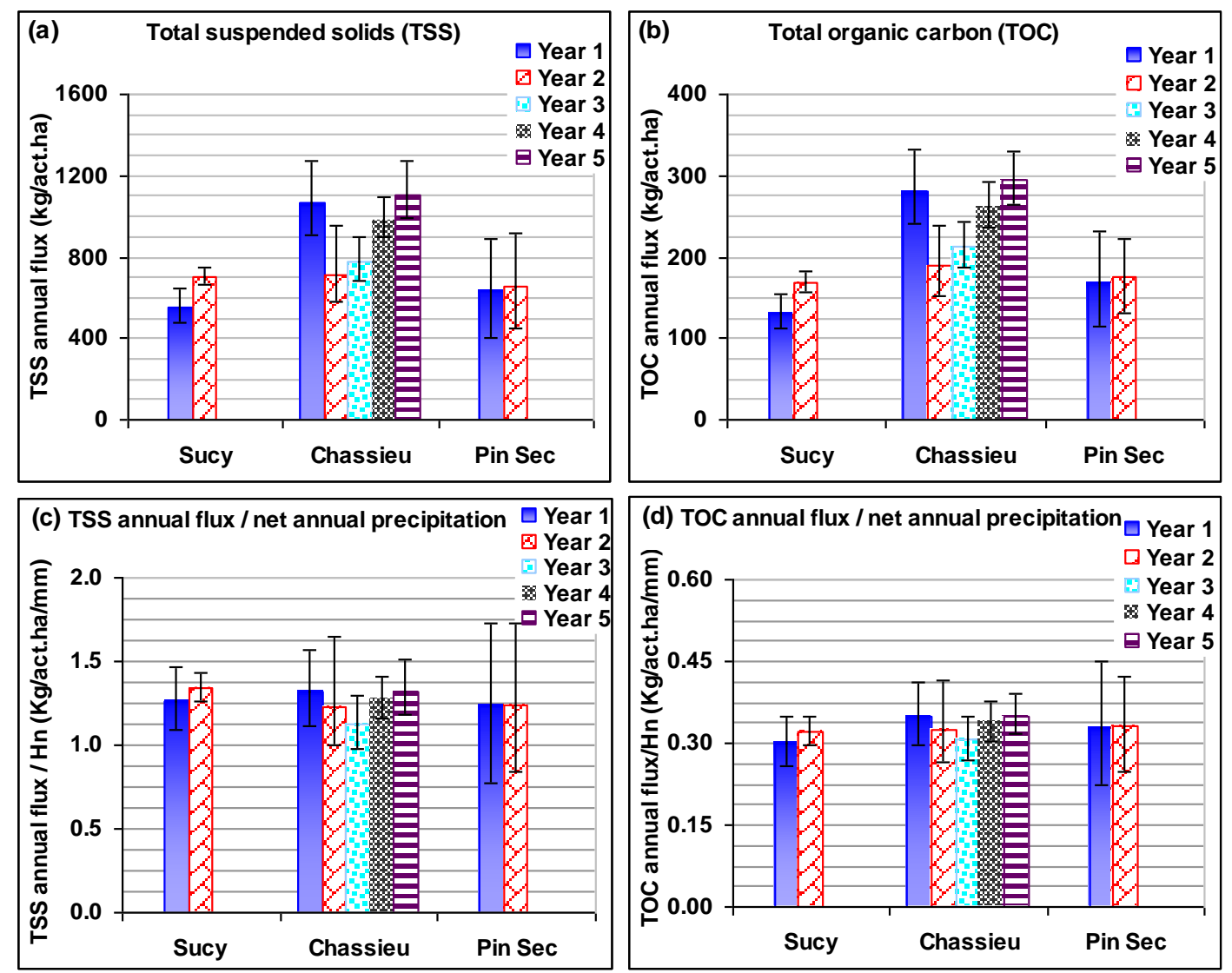

Figure 7: Annual loads at each site (average value from all simulations): (a) TSS annual loads; (b): TOC annual loads; (c) (respectively (d)): TSS (resp. TOC) annual loads per mm of water (net, see Table 4). Error bars represent the $95 \%$ empirical confidence intervals

Similarly, the same trend can be observed for TOC specific annual loads (between 130 and $175 \mathrm{~kg} / \mathrm{act} . \mathrm{ha} /$ year in Sucy and Pin Sec and between 190 and $295 \mathrm{~kg} / \mathrm{act}$.ha/year in Chassieu). At each site, uncertainties on TSS loads and TOC loads vary from one year to another depending on the amount of available data. This dispersion (around the mean value at $95 \%$ CI) varies from 5 to $15 \%$ in Sucy site, from 10 to 35\% in Chassieu site and from 30 to $40 \%$ in Pin Sec site. Indeed, two factors affect the uncertainties of TSS loads on the same site: measurement uncertainties and those caused by selected models due to the absence of measurements. The effect of data reconstitution can be spotted on Sucy and Pin Sec, where fewer data is available in 2011 than in 2012 from flow rate and/or turbidity monitoring and in Chassieu where fewer data is available for 2004 and 2005 than for other years due to failures of the measurement system. In addition, the absence of a turbidity measurement in Pin Sec site involves uncertainties on the evaluation of annual loads higher than those observed in Sucy and Chassieu sites.

For temporal variations, we can observe a low inter-annual variability of TSS load with an apparent influence of meteorological conditions expressed as annual precipitation (Figure 7, (c)). Indeed, the annual load per $\mathrm{mm}$ water (net) represents a Site (discharge-weighted) Mean Concentration (SMC). So, the SMC during a given year will be $S M C(m g / l) \cong 10^{2} \frac{M(\mathrm{~kg} / \mathrm{act} . \mathrm{ha})}{H_{n}(\mathrm{~mm})}$ (Equation 10). In other words, the overall TSS SMC is about $130 \pm 15 \mathrm{mg} / \mathrm{l}$ in Sucy, $125 \pm 45 \mathrm{mg} / \mathrm{l}$ in Pin Sec and $125 \pm 20 \mathrm{mg} / \mathrm{l}$ in Chassieu at a confidence level 95\%. TSS SMC uncertainty in Pin Sec site is important $(\sim \pm 35 \%)$ because it is derived from a small number of rainfall events $(n=18)$. This latter confirms the results of 
(Mourad et al. 2005) which stressed that using fewer than 20 sampled rainfall events leads to uncertainties on TSS SMC above 30\% (95\% half-confidence interval).

Likewise, the overall TOC SMC is about $31 \pm 4 \mathrm{mg} / \mathrm{l}$ in Sucy, $33 \pm 10 \mathrm{mg} / \mathrm{l}$ in Pin Sec and $33 \pm 5$ $\mathrm{mg} / \mathrm{l}$ in Chassieu at a $95 \%$ confidence level. Low uncertainties in SS and TOC SMC in Sucy and Chassieu sites demonstrates that the use of turbidity monitoring, as indicator of TSS concentration, substantially improves the accuracy of evaluated annual pollutant load.

\section{Annual loads of micropollutants}

476 Annual loads of $\mathrm{Pb}, \sum \mathrm{OP}, \sum{ }_{16} \mathrm{PAH}$ and $\sum{ }_{9} \mathrm{PBDE}$ per active hectare are shown in Figure 8. The loads are presented for Sucy and Pin Sec sites. For Chassieu the PAH and PBDE loads are not calculated, due to limited number of sampled events. The annual loads of all studied pollutants for all years and their overall SMC are shown in Table 5.

We notice an interannual and intersite variability of annual pollutant loads, as for TSS annual loads. At each site, we observe an interannual variability influenced by meteorological conditions (Table 4). The inter-site variability of pollutants annual loads per mm water is logically linked to the calibration of distribution models of pollutants EMCs. Indeed, for pollutant displaying site-to-site differences between Sucy and Pin Sec sites ( ${ }_{16} P A H$ and $\sum_{9} P B D E$ (see Figure 7 and Figure $8(c$ and $d)$ ), pollutants annual loads per mm are different between sites. For example, in spite of similar annual precipitation, the $\sum_{16} P A H$ loads in $S u c y$ site are two times higher than those in Pin Sec site, but $\sum_{9} P B D E$ loads in Sucy are ten times lower than those in Pin Sec, reflecting local contamination.

The Uncertainty on annual loads of different pollutants (at 95\% CI) varies between 10 and $60 \%$, and may reach $100 \%$ as in the case of $\sum_{9} P B D E$ in Pin Sec site (see Figure $8(d)$ ). Indeed, we can observe two types of the uncertainties of pollutants loads: i) Loads estimated using model M4: (taking into account the correlation between TSS and pollutant concentration for $\mathrm{Zn}, \mathrm{Cu}, \mathrm{Cr}$, As, Ni, Pb, Sr, V, $\sum \mathrm{NP}, \sum_{16} \mathrm{PAH}$ (Sucy) and $\sum_{13} \mathrm{PAH}$ (Sucy)) have dispersion less than $30 \%$ around its average values; ii) By comparison those estimated from model M3 (pollutant uncorrelated with TSS like Cd, Co, Pt, Ti, Mo, BDE-209, $\sum_{9} \mathrm{PBDE}, \mathrm{BPA}, \sum \mathrm{OP}, \sum_{16} \mathrm{PAH}$ (Pin Sec), $\sum_{13} \mathrm{PAH}$ (Pin Sec)) have dispersion greater than $30 \%$ around its average values and these uncertainties rise to more than $100 \%$ in some cases. This shows the importance of a continuous measurement of turbidity minimizing uncertainties in the estimation of annual loads of pollutants attached to solid particles. This point will be illustrated below to show the importance of considering the correlation between TSS and pollutant particulate concentration in the calculation method. 

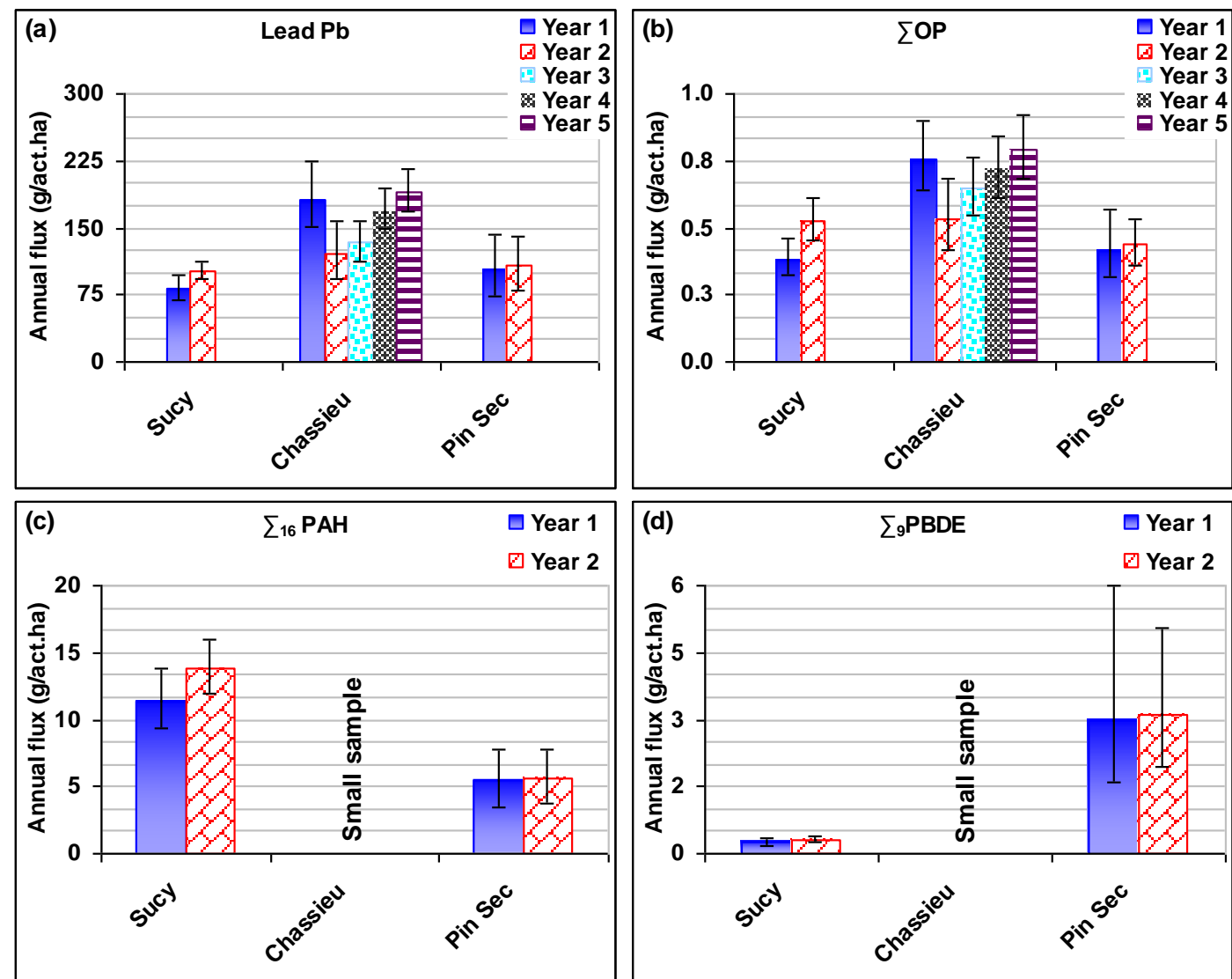

Figure 8: Annual loads at each site of: (a): Lead Pb; (b) sum of Octylphenols $\sum \mathrm{OP}$; (c) sum 16 polycyclic aromatic hydrocarbons $\sum 16 \mathrm{PAH}$ and (d) sum of 9 polybromodiphenylethers $\sum 9 \mathrm{PBDE}$. Error bars represent the 95\% empirical confidence intervals. Years 1 and 2: 2011 and 2012 at Sucy \& Pin Sec sites, and Years 1 to 5: 2004 to 2008 at Chassieu site.

\section{Efficiency of turbidity monitoring to reduce uncertainties in annual pollutant loads}

To illustrate the impact of correlation $\rho$ between TSS EMC and $C_{P-P o l} E M C$, three cases are simulated and compared for a pollutant having a particulate concentration highly correlated with the concentration of TSS (cases of lead $\mathrm{Pb}$ for example, see Figure 4 and Figure 8): i) $\rho$ considered as equal to 0 using model M3; ii) $\rho$ considered with its actual value and using model M4 with TSS analyzed on water samples, iii) $\rho$ considered with its actual value using model M4 with TSS assessed from continuous turbidity measurement. The uncertainties involved by the runoff model M1 can be neglected for comparison purpose: uncertainties obtained by this calculation are due only to errors from models M2 (TSS distribution) and M4 (solute distribution plus TSS correlation).

Figure 9 show that this correlation changes the average annual loads as well as its uncertainties. We don't know the "exact value" of $P b$ annual load to validate the average $P b$ annual load obtained for each case. Anyway, the information provided by $\mathrm{Pb}$-TSS correlation lowers the relative uncertainty on the annual concentration, especially if continuous monitoring if turbidity is available. The improvement of the uncertainty observed for case $i i$ is explained by the number of events sampled for TSS analysis being larger than the number of events sampled for $\mathrm{Pb}$ analysis: 121 rainfall events vs. 24 sampled rainfall events. 


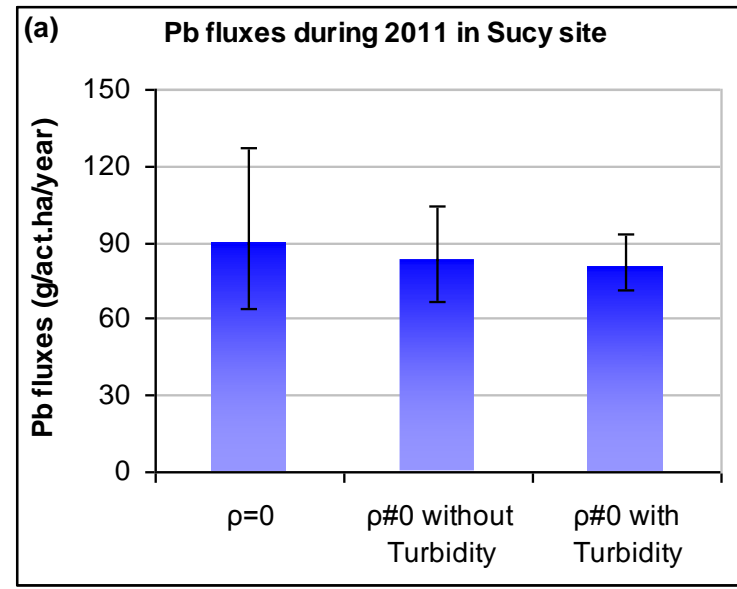

Figure 9: Impact of the correlation between TSS EMC and pollutant particulate EMC with or without turbidity measurements (cases of lead Pb in Sucy site, year 2011) 


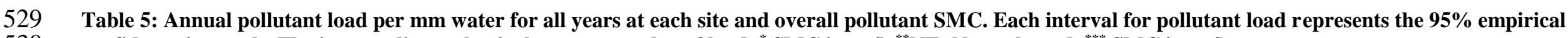

530 confidence intervals. The intermediate value is the average value of load. ${ }^{*} \mathrm{SMC}$ in $\mu \mathrm{g} / \mathrm{l}$. ${ }^{* *} \mathrm{NE}:$ No evaluated. ${ }^{* * *} \mathrm{SMC}$ in ng/l

\begin{tabular}{|c|c|c|c|c|c|c|c|c|c|c|c|c|c|c|c|}
\hline $\begin{array}{l}\text { Load (mg/ } \\
\text { act.ha/mm) }\end{array}$ & $\begin{array}{l}\text { Poll- } \\
\text { utant }\end{array}$ & As & Cd & Co & $\mathrm{Cr}$ & $\mathrm{Cu}$ & Mo & $\mathrm{Ni}$ & $\mathbf{P b}$ & \multicolumn{2}{|c|}{$\mathbf{P t}$} & \multicolumn{2}{|c|}{$\mathrm{Sr}$} & $\mathrm{Ti}$ & V \\
\hline \multirow{3}{*}{ Sucy } & 2011 & {$[12 ; 14 ; 15]$} & {$[2 ; 2.6 ; 3.4]$} & {$[24 ; 31 ; 40]$} & {$[26 ; 31 ; 39]$} & {$[280 ; 370 ; 490]$} & {$[33 ; 48 ; 68]$} & {$[37 ; 43 ; 51]$} & {$[160 ; 185 ; 220]$} & \multicolumn{2}{|c|}{$[0.34 ; 0.48 ; 0.67]$} & \multicolumn{2}{|c|}{$[920 ; 1085 ; 1285]$} & {$[185 ; 245 ; 330]$} & {$[38 ; 43 ; 50]$} \\
\hline & 2012 & {$[14 ; 15 ; 16]$} & {$[2.3 ; 2.8 ; 3.4]$} & {$[28 ; 33 ; 40]$} & {$[30 ; 33 ; 36]$} & {$[330 ; 380 ; 450]$} & {$[40 ; 54 ; 74]$} & {$[42 ; 47 ; 53]$} & {$[180 ; 195 ; 215]$} & \multicolumn{2}{|c|}{$[0.42 ; 0.54 ; 0.72]$} & \multicolumn{2}{|c|}{$[1070 ; 1220 ; 1400]$} & [215;255;305] & {$[43 ; 47 ; 51]$} \\
\hline & SMC $^{\star}$ & $1.4 \pm 0.1$ & $0.27 \pm 0.04$ & $3.2 \pm 0.5$ & $3.2 \pm 0.4$ & $38 \pm 6$ & $5.1 \pm 1.4$ & $4.5 \pm 0.4$ & $19 \pm 2$ & \multicolumn{2}{|c|}{$0.05 \pm 0.01$} & \multicolumn{2}{|c|}{$116 \pm 12$} & $25 \pm 4$ & $4.5 \pm 0.4$ \\
\hline \multirow{3}{*}{ Pin Sec } & 2011 & {$[39 ; 45 ; 53]$} & [1.9;2.8;4.2] & [23;33;49] & {$[27 ; 34 ; 44]$} & {$[290 ; 410 ; 600]$} & {$[26 ; 44 ; 80]$} & {$[35 ; 44 ; 57]$} & {$[145 ; 205 ; 275]$} & \multicolumn{2}{|c|}{$[0.27 ; 0.45 ; 0.77]$} & \multicolumn{2}{|c|}{$[250 ; 330 ; 430]$} & {$[190 ; 270 ; 400]$} & {$[38 ; 45 ; 55]$} \\
\hline & 2012 & {$[41 ; 46 ; 51]$} & {$[2.2 ; 2.8 ; 3.7]$} & {$[26 ; 33 ; 43]$} & {$[30 ; 35 ; 41]$} & {$[325 ; 413 ; 535]$} & {$[31 ; 45 ; 67]$} & [38;44;53] & {$[150 ; 200 ; 265]$} & \multicolumn{2}{|c|}{$[0.32 ; 0.45 ; 0.65]$} & \multicolumn{2}{|c|}{$[275 ; 330 ; 395]$} & {$[215 ; 270 ; 355]$} & {$[40 ; 46 ; 52]$} \\
\hline & SMC $^{*}$ & $4.6 \pm 0.4$ & $0.28 \pm 0.06$ & $3.3 \pm 0.7$ & $3.4 \pm 0.8$ & $41 \pm 10$ & $4.5 \pm 1.7$ & $4.4 \pm 0.9$ & $20 \pm 4$ & \multicolumn{2}{|c|}{$0.05 \pm 0.02$} & \multicolumn{2}{|c|}{$33 \pm 6$} & $27 \pm 7$ & $4.5 \pm 0.5$ \\
\hline & 2004 & {$[12 ; 15 ; 17]$} & \begin{tabular}{|l|}
{$[2.1 ; 3 ; 3.6]$} \\
\end{tabular} & {$[26 ; 35 ; 43]$} & & {$[295 ; 440 ; 540]$} & & {$[39 ; 49 ; 57]$} & {$[160 ; 225 ; 280]$} & \multicolumn{2}{|c|}{$[0.32 ; 0.51 ; 0.65]$} & \multicolumn{2}{|c|}{$[950 ; 1220 ; 1430]$} & {$[195 ; 290 ; 355]$} & {$[41 ; 50 ; 57]$} \\
\hline & 2005 & {$[10 ; 14 ; 16]$} & {$[1.5 ; 2.8 ; 3.6]$} & [19;33;42] & & [210;410;520] & & {$[32 ; 47 ; 57]$} & {$[110 ; 210 ; 270]$} & \multicolumn{2}{|c|}{$[0.23 ; 0.5 ; 0.66]$} & \multicolumn{2}{|c|}{$[770 ; 1150 ; 1400]$} & {$[140 ; 270 ; 350]$} & {$[34 ; 47 ; 56]$} \\
\hline choroig & 2006 & {$[11 ; 13 ; 15]$} & {$[2 ; 2.7 ; 3.2]$} & {$[24 ; 31 ; 38]$} & $\mathbf{N E}^{\star *}$ & {$[275 ; 375 ; 460]$} & $\mathbf{N E}^{\star *}$ & {$[36 ; 45 ; 52]$} & {$[150 ; 190 ; 220]$} & {$[0.33 ;$} & $51 ; 0.65]$ & {$[890 ; 10$} & $5 ; 1265]$ & {$[180 ; 250 ; 300]$} & {$[38 ; 44 ; 50]$} \\
\hline chassieu & 2007 & {$[13 ; 14 ; 16]$} & {$[2.2 ; 2.9 ; 3.4]$} & {$[26 ; 34 ; 41]$} & INE & {$[330 ; 425 ; 495]$} & INE & {$[38 ; 48 ; 55]$} & {$[180 ; 220 ; 240]$} & {$[0.33 ;$} & $51 ; 0.64]$ & {$[975 ; 1$} & $5 ; 1360]$ & {$[215 ; 280 ; 330]$} & {$[43 ; 49 ; 54]$} \\
\hline & 2008 & {$[13 ; 15 ; 16]$} & {$[2.3 ; 3 ; 3.5]$} & {$[27 ; 36 ; 42]$} & & {$[340 ; 440 ; 515]$} & & {$[41 ; 49 ; 56]$} & {$[180 ; 225 ; 250]$} & {$[0.34 ;$} & $2 ; 0.64]$ & {$[1020 ; 1$} & $25 ; 1400]$ & [220;290;345] & {$[44 ; 50 ; 56]$} \\
\hline & SMC $^{*}$ & $1.4 \pm 0.1$ & $0.29 \pm 0.03$ & $3.4 \pm 0.4$ & & $42 \pm 5$ & & $4.8 \pm 0.4$ & $21 \pm 2$ & 0.05 & 0.01 & $11 \varepsilon$ & \pm 10 & $28 \pm 3$ & $4.84 \pm 0.33$ \\
\hline 531 & & & & & & & & & & & & & & & \\
\hline & (mg/a & $\begin{array}{l}\text { Load } \\
\text { ct.ha/mm) }\end{array}$ & Pol & Ilutant & $\sum_{16} \mathrm{PAH}$ & $\sum{ }_{13} \mathrm{PAl}$ & & DE-209 & $\sum{ }_{9} \mathrm{~PB}$ & & & PA & & $\sum O P$ & $\sum \mathbf{N P}$ \\
\hline & & & & 2011 & {$[20 ; 26 ; 32]$} & {$[20 ; 24 ; 31]$} & {$[0.38 ; 0$.} & $5 ; 0.8]$ & {$[0.41 ; 0.58 ; 0 . \varepsilon$} & & {$[3.7 ; 4.6$} & ;5.6] & {$[0.73 ; 0 . \varepsilon$} & $87 ; 1.05]$ & {$[10 ; 12 ; 15]$} \\
\hline & & Sucy & & 2012 & {$[22 ; 26 ; 31]$} & [22;24;29] & {$[0.45 ; 0$.} & $8 ; 0.74]$ & {$[0.48 ; 0.6 ; 0.77$} & & {$[4.4 ; 5.2$} & ;6.2] & {$[0.86 ; 1 ; 1]$} & $1.16]$ & {$[11 ; 13 ; 15]$} \\
\hline & & & & $M \mathbf{C}^{\star \star \star}$ & $2600 \pm 400$ & $2400 \pm 35$ & $57 \pm 10$ & & $59 \pm 12$ & & $490 \pm$ & & $95 \pm 10$ & & $1240 \pm 150$ \\
\hline & & & & 2011 & {$[9 ; 11 ; 13]$} & {$[7 ; 9 ; 10]$} & {$[0.3$} & ;0.58;1.17] & {$[0.3 ; 0.58$} & $1.21]$ & & ;4.2;6] & {$[0.61$} & $1 ; 0.81 ; 1.11]$ & {$[9 ; 12 ; 16]$} \\
\hline & & in Sec & & 2012 & {$[9 ; 11 ; 12]$} & {$[8 ; 9 ; 10]$} & {$[0.3$} & ;0.59;0.99] & {$[0.37 ; 0.59$} & $0.97]$ & {$[3.5$} & $4.3 ; 5.4]$ & {$[0.68$} & $8 ; 0.82 ; 1.01]$ & {$[10 ; 12 ; 15]$} \\
\hline & & & & $\mathrm{MC}^{\star \star \star}$ & $1060 \pm 12$ & $875 \pm 10$ & & $8 \pm 33$ & $58 \pm$ & & & \pm 90 & & $30 \pm 15$ & $1190 \pm 250$ \\
\hline & & & & 2004 & & & & & & & {$[4 ;$} & $.9 ; 5.9]$ & {$[0.79$} & $9 ; 0.93 ; 1.11]$ & {$[10 ; 13 ; 15]$} \\
\hline & & & & 2005 & & & & & & & {$[3.2$} & $4.8 ; 5.8]$ & {$[0.6$} & $5 ; 0.92 ; 1.1]$ & {$[8 ; 12 ; 15]$} \\
\hline & & & & 2006 & & & NI & & & & {$[3.9$} & $4.9 ; 5.7]$ & {$[0.76$} & $6 ; 0.93 ; 1.07]$ & {$[10 ; 12 ; 14]$} \\
\hline & & Iassieu & & 2007 & & & NE & & & & {$[3.8$} & $4.8 ; 5.7]$ & {$[0.77$} & $7 ; 0.93 ; 1.06]$ & {$[10 ; 12 ; 14]$} \\
\hline & & & & 2008 & & & & & & & {$[4 ;$} & $9 ; 5.7]$ & {$[0.79$} & $9 ; 0.94 ; 1.08]$ & {$[11 ; 13 ; 15]$} \\
\hline & & & & $M C^{\star \star \star}$ & & & & & & & & \pm 50 & & $95 \pm 10$ & $1240 \pm 110$ \\
\hline
\end{tabular}




\section{CONCLUSIONS}

533 A method was developed to set up annual pollutant loads and its uncertainties using a large dataset of pollutant EMC and continuous turbidity, flow rate and rainfall intensity recordings. This stochastic method is original and allows the coupling between a few event sampling campaigns and continuous measurements of hydrological and water quality parameters (rainfall intensity, flow rate, turbidity).

The results obtained can be summarized as follows:

- Lognormal distributions are well suited to describe pollutant EMC;

- The inter-annual variability of the pollutant annual loads in a given site are mainly influenced by weather conditions (annual precipitation);

- The inter-site variability of the pollutant annual loads per mm of water is related to the distribution of EMC of target pollutant.

- Annual loads of pollutants can be estimated with uncertainties ranging from $10 \%$ to $60 \%$ and can reach $100 \%$ for some pollutants. For the pollutants with a particulate fraction not correlated to TSS concentrations, the dispersion is greater than $30 \%$. For the pollutants highly correlated with TSS concentration, this dispersion can be significantly reduced (10\% to $30 \%)$ if we have information about TSS concentration (continuous measurement of turbidity).

A continuous measurement of turbidity can improve the estimation of annual loads of some pollutants attached to solid particles. Such results can be used to identify priority sources of pollution and then direct preventive / curative actions.

It would be worthwhile to pursue this line of research at other sites as a preliminary step to generalization.

\section{ACKNOWLEDGMENTS}

556

557

558

559

560

561

562

563

This study has been conducted within the framework of the INOGEV research program, which was funded by the French National Research Agency (under its "Sustainable Cities" program). The authors would like to thank all project partners, namely the Greater Lyon and RM\&C Water Agency, the Nantes Metropolitan Council, the Val-de-Marne Council for their technical and financial support, as well as the French Observatories OPUR, OTHU and ONEVU plus the SOERE URBIS for their scientific contributions. We also highly appreciate the contributions of the authors of papers (Gasperi et al. 2014, Metadier and BertrandKrajewski 2012) for collecting and sharing datasets of studied sites.

\section{REFERENCES}

2013/39/EU Directive 2013/39/EU of the european parliament and of the council of 12 August 2013: amending Directives 2000/60/EC and 2008/105/EC as regards priority substances in the field of water policy. Official Journal of the European Union, L 226.

Ashley, R., Bertrand-Krajewski, J.L. and Hvitved-Jacobsen, T. (2005) Sewer solids - 20 years of investigation. Water Science and Technology 52(3), 73-84.

Becouze-Lareure, C., Dembélé, A., Coquery, M., Cren-Olivé, C. and Bertrand-Krajewski, J.L. (2011) Mass balances of priority pollutants from different sources in urban wet weather discharges, p. 8, Porto Alegre/Brazil, 11-16 September 2011.

Clark, S.E., Burian, S., Pitt, R. and Field, R. (2007) Urban wet-weather flows. Water Environment Research 79(10), 1166-1227.

EPA, N. (2005) Alex Maestre and Robert Pitt, The National Stormwater Quality Database, Version 1.1. A Compilation and Analysis of NPDES,Stormwater Monitoring Information. Department of Civil and Environmental Engineering 
The University of Alabama Tuscaloosa, AL 35294, p. 447.

Francey, M., Fletcher, T.D., Deletic, A. and Duncan, H. (2010) New Insights into the Quality of Urban Storm Water in South Eastern Australia. Journal of Environmental Engineering-

581 Asce 136(4).

582

583

584

585

586 Gasperi, J., Sebastian, C., Ruban, V., Delamain, M., Percot, S., Wiest, L., Mirande, C., R., Chebbo, G., Cren, C., Millet, M., S, B. and Gromaire, M.C. (2014) "Micropollutants in urban stormwater: occurrence, concentrations, and atmospheric contributions for a wide range of contaminants in three French catchments". Environmental Science and Pollution Research, 2014 Apr;21(8):5267-81.

Gromaire, M-C., Cabane, P.,Bertrand-Krajewski, J.L., Chebbo, G. (2007). "Utilisation des modèles de calcul des flux polluants en assainissement: résultats d'une enquête en France" (Using pollutant fluxes calculation models in sewer system: results of a survey in France). La Houille Blanche - Revue internationale de l'eau, EDP Sciences, 2007, 2007 (2), pp.94.

Gromaire, M.C. and Chebbo, G. (2001) Pollutant concentration measurement uncertainties in sewage. Houille Blanche-Revue Internationale De L Eau (6-7), 109-114.

Hannouche, A., Chebbo, G., Ruban, G., Tassin, B., Lemaire, B.J. and Joannis, C. (2011) Relationship between turbidity and total suspended solids concentration within a combined sewer system. Water Science and Technology 64(12), 2445-2452.

ISO/IEC (2008) ISO/IEC Guide 98-3/Suppl.1:2008(E) Uncertainty of measurement - Part 3: Guide to the expression of uncertainty in measurement (GUM:1995) Supplement 1: Propagation of distributions using a Monte Carlo method. Geneva (Switzerland): ISO, 2008, $98 \mathrm{p}$.

Joannis, C., Ruban, G., Gromaire, M.C., Bertrand-Krajewski, J.L. and Chebbo, G. (2008) Reproducibility and uncertainty of wastewater turbidity measurements. Water Science and Technology 57(10), 1667-1673.

Lacour, C., Joannis, C. and Chebbo, G. (2009) Assessment of annual pollutant loads in combined sewers from continuous turbidity measurements: Sensitivity to calibration data. Water Research 43(8), 2179-2190.

Langeveld, J.G., Veldkamp, R.G. and Clemens, F. (2005) Suspended solids transport: an analysis based on turbidity measurements and event based fully calibrated hydrodynamic models. Water Science and Technology 52(3), 93-101.

Metadier, M. and Bertrand-Krajewski, J.L. (2011) From mess to mass: a methodology for calculating storm event pollutant loads with their uncertainties, from continuous raw data time series. Water Science and Technology 63(3), 369-376.

Metadier, M. and Bertrand-Krajewski, J.L. (2012) The use of long-term on-line turbidity measurements for the calculation of urban stormwater pollutant concentrations, loads, pollutographs and intra-event fluxes. Water research 46(20).

Mourad, M., Bertrand-Krajewski, J.L. and Chebbo, G. (2005) Sensitivity to experimental data of pollutant site mean concentration in stormwater runoff. Water Science and Technology 51(2), 155-162.

Mourad, M. and Bertrand-Kralewski, J.L. (2002) A method for automatic validation of long time series of data in urban hydrology. Water Science and Technology 45(4-5), 263-270.

Romeu, J.L. (2002) Empirical assessment of normal and lognormal distribution assumptions. RAC START "Reliability Analysis Center, Selected Topics in Assurance Related Technologies". Volume 9, Number 6. Available online (http://src.alionscience.com/pdf/NLDIST.pdf).

Romeu, J.L. (2003) Kolmogorov-Simirnov: A Goodness of Fit Test for Small Samples. RAC START "Reliability Analysis Center, Selected Topics in Assurance Related Technologies". Volume 10, Number 6. Available online (https://src.alionscience.com/pdf/K_STest.pdf). 
Ruban, G., Mabilais, D. and Lemaire, K. (2010) Particle characterization of urban wetweather discharges: methods and related uncertainties, p. 10, Graie, Lyon, France. Sebastian, C., Ruban V., Moilleron R., Barraud S., Chebbo G., Gromaire M-C., Lorgeoux C., Gasperi J., Cren C., Wiest L., Demare D., Millet M., Saad M., Percot S. and D., M. (2011), INOGEV project - an original French approach in micropollutant characterization assessment in urban wet weather effluents and atmospheric deposits. 12nd International Conference on Urban Drainage, Porto Alegre/Brazil, 10-15 September 2011.

Smullen, J.T., Shallcross, A.L. and Cave, K.A. (1999) Updating the US nationwide urban runoff quality data base. Water Science and Technology 39(12), 9-16.

Weiss, P., G. LeFevre and Gulliver, J. (2008) Contamination of Soil and Groundwater Due to Stormwater Infiltration Practices: a Literature Review. University of Minnesota St. Anthony Falls Laboratory Project Report No.515. Prepared for Minnesota Pollution Control Agency.
Available
June
23, $\quad 2008$
www.pca.state.mn.us/index.php/downloaddocument.html?gid=7732.

Zgheib, S., Moilleron, R. and Chebbo, G. (2012) Priority pollutants in urban stormwater: Part 1-Case of separate storm sewers. Water Research 46(20), 6683-6692.

\section{SUPPLEMENTARY MATERIALS}

645

646

647

648

649

650

651

Table 6: General characteristics of sampled rainfall events followed by a laboratory analysis in the three studied sites (min-max and median values) (Gasperi et al. 2014)

\begin{tabular}{|c|ccccc|}
\hline & $\mathrm{H}^{1}(\mathrm{~mm})$ & Duration $(\mathrm{h})$ & $\mathrm{I}_{\text {mean }}\left(\mathrm{mm} \cdot \mathrm{h}^{-1}\right)$ & $\mathrm{I}_{\max }{ }^{2}\left(\mathrm{~mm}^{-1} \mathrm{~h}^{-1}\right)$ & $\mathrm{PDWP}^{3}(\mathrm{~d})$ \\
\hline Sucy & $1.2-38.6$ & $0.6-26.3$ & $0.4-3.8$ & $2.4-24$ & $0.17-9.18$ \\
$(\mathrm{n}=24)$ & 8.43 & 7.9 & 1.5 & 7.9 & 2.1 \\
\hline Chassieu & $2.4-50.0$ & $3.1-31.6$ & $0.8-1.7$ & $4.7-22.7$ & $0.2-9.8$ \\
$(\mathrm{n}=7)$ & 18.8 & 14.5 & 1.2 & 12.2 & 2.8 \\
\hline Pin Sec & $2.3-49.9$ & $2.7-60.5$ & $0.3-4.0$ & $2.4-28.8$ & $0.19-22.29$ \\
$(\mathrm{n}=18)$ & 15.4 & 19.2 & 0.8 & 11.4 & 2.60 \\
\hline \multicolumn{7}{l}{ 1) Precipitation depth; 2) Imax evaluated over 5-min intervals; 3) Preceding dry weather period, in days. Min-Max } \\
values, as well as median values;
\end{tabular}

Table 7: Pollutants analyzed and number of rainfall events (Gasperi et al. 2014)

\begin{tabular}{|c|c|c|}
\hline Groups $(n=46)$ & $\begin{array}{c}\text { Number of } \\
\text { rainfall events }\end{array}$ & Substances and abbreviations \\
\hline \multirow{3}{*}{$\begin{array}{l}\text { Metals } \\
(n=13)\end{array}$} & Sucy: 8 & \multirow{3}{*}{$\begin{array}{l}\text { Arsenic (As), Cadmium }(\mathrm{Cd}) \text {, Chromium }(\mathrm{Cr}) \text {, Copper }(\mathrm{Cu}) \text {, Nickel } \\
(\mathrm{Ni}) \text {, Lead }(\mathrm{Pb}) \text {, Zinc }(\mathrm{Zn}) \text {, Platinum }(\mathrm{Pt}) \text {, Vanadium }(\mathrm{V}) \text {, Cobalt } \\
(\mathrm{Co}) \text {, Molybdenum (Mo), Strontium (Sr), Titan (Ti) }\end{array}$} \\
\hline & & \\
\hline & & \\
\hline \multirow{3}{*}{$\begin{array}{l}\text { PAH } \\
(\mathrm{n}=16)\end{array}$} & & \multirow{3}{*}{ 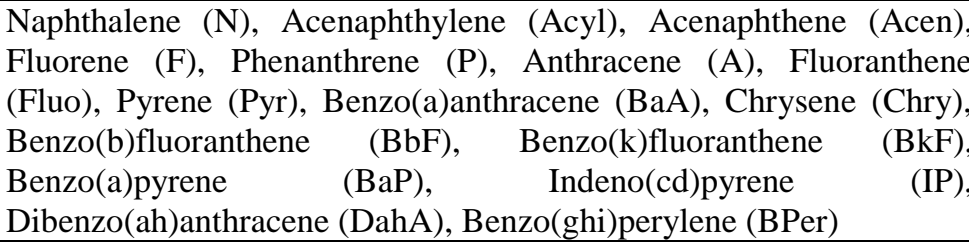 } \\
\hline & Pin Sec: 7 & \\
\hline & Chassieu: 4 & \\
\hline \multirow{3}{*}{$\begin{array}{c}\text { PBDE } \\
(\mathrm{n}=9)\end{array}$} & Sucy: 12 & \multirow{3}{*}{$\begin{array}{l}\text { BDE-28 [tri], BDE-47 [tetra], BDE-99 [penta], BDE-100 [penta], } \\
\text { BDE-153 [hexa], BDE-154 [hexa], BDE-183 [hepta], BDE-205 } \\
\text { [octa], BDE-209 [deca] }\end{array}$} \\
\hline & Pin Sec: 7 & \\
\hline & & \\
\hline \multirow{3}{*}{$\begin{array}{l}\text { Bisphenol A and } \\
\text { APnEOs } \\
(\mathrm{n}=1+7)\end{array}$} & Sucy: 12 & \multirow{3}{*}{$\begin{array}{l}\text { Bisphenol A (BPA) } \\
\text { Nonylphenol (NP), nonylphenol monoethoxylate (NP1EO), } \\
\text { nonylphenol diethoxylate (NP2EO), nonylphenol monocarboxylate } \\
\text { (NP1EC), 4-tert-octylphenol (OP), octylphenol monoethoxylate } \\
\text { (OP1EO), octylphenol diethoxylate (OP2EO) }\end{array}$} \\
\hline & Pin Sec: 7 & \\
\hline & Chassieu: 2 & \\
\hline
\end{tabular}


Table 8: Parameters of distributions in natural logarithm space ( $\mu$ and $\sigma)$ for models $M 3$ ( $\left.C_{\text {T-pol }}\right)$ ditribution) and M4 ( $\mathrm{C}_{\mathrm{D} \text {-pol }}+\tau$ distributionS). See equations 9 and 10 to switch from the logarithmic space to arithmetic space ( $m$ and SD). Note: The units are given in the arithmetic space

\begin{tabular}{|c|c|c|c|c|c|c|c|c|c|c|c|c|c|c|}
\hline \multicolumn{7}{|c|}{ Model M3 : $C_{T-p o l}$ (unit) } & \multicolumn{8}{|c|}{ Model M4: $\xi$ (unit*1/mg TSS) and $C_{d-p o l}$ (unit) } \\
\hline \multirow{2}{*}{ Substance } & \multicolumn{2}{|c|}{ Sucy } & \multicolumn{2}{|c|}{ Chassieu } & \multicolumn{2}{|c|}{ Pin Sec } & \multirow{2}{*}{ Substance } & \multirow{2}{*}{$\begin{array}{c}\tau \text { and } \\
C_{d}\end{array}$} & \multicolumn{2}{|c|}{ Sucy } & \multicolumn{2}{|c|}{ Chassieu } & \multicolumn{2}{|c|}{ Pin Sec } \\
\hline & $\mu$ & $\sigma$ & $\mu$ & $\sigma$ & $\mu$ & $\sigma$ & & & $\mu$ & $\sigma$ & $\mu$ & $\sigma$ & $\mu$ & $\sigma$ \\
\hline \multirow{2}{*}{$\mathrm{Cd}(\mu \mathrm{g} / \mathrm{l})$} & \multirow{2}{*}{$\begin{array}{c}- \\
1.47\end{array}$} & \multirow{2}{*}{0.81} & \multirow{6}{*}{\multicolumn{2}{|c|}{$\begin{array}{l}\text { pooled with } \\
\text { Sucy }{ }^{*}\end{array}$}} & \multirow{8}{*}{\multicolumn{2}{|c|}{ as $S u c y$}} & \multirow{2}{*}{$\begin{array}{c}\text { TOC } \\
(\mathrm{mg} / \mathrm{l})\end{array}$} & $\tau$ & 1.58 & 0.21 & \multirow{6}{*}{\multicolumn{2}{|c|}{$\begin{array}{c}\text { pooled } \\
\text { with Sucy }\end{array}$}} & \multirow{8}{*}{\multicolumn{2}{|c|}{$\begin{array}{l}\text { pooled with } \\
\text { Sucy }\end{array}$}} \\
\hline & & & & & & & & $C_{d-p o l}$ & 1.53 & 0.75 & & & & \\
\hline $\mathrm{Co}(\mu \mathrm{g} / \mathrm{l})$ & 0.95 & 0.77 & & & & & $\mathrm{Zn}$ & $\tau$ & 0.42 & 0.26 & & & & \\
\hline $\operatorname{Pt}(\mu \mathrm{g} / \mathrm{l})$ & $\begin{array}{c}- \\
3.39\end{array}$ & 0.92 & & & & & $(\mu \mathrm{g} / \mathrm{l})$ & $C_{d-p o l}$ & 3.82 & 0.43 & & & & \\
\hline \multirow{2}{*}{$\mathrm{Ti}(\mu \mathrm{g} / \mathrm{l})$} & \multirow{2}{*}{2.98} & \multirow{2}{*}{0.84} & & & & & \multirow{2}{*}{$\begin{array}{c}\mathrm{Cu} \\
(\mu \mathrm{g} / \mathrm{l})\end{array}$} & $\tau$ & -1.28 & 0.43 & & & & \\
\hline & & & & & & & & $C_{d-p o l}$ & 1.58 & 0.55 & & & & \\
\hline \multirow{2}{*}{ Mo $(\mu \mathrm{g} / \mathrm{l})$} & \multirow{2}{*}{1.15} & \multirow{2}{*}{0.98} & & & & & \multirow{2}{*}{$\begin{array}{c}\mathrm{Cr} \\
(\mu \mathrm{g} / \mathrm{l})\end{array}$} & $\tau$ & -3.52 & 0.27 & \multirow{6}{*}{\multicolumn{2}{|c|}{$\begin{array}{c}\text { Small } \\
\text { sample: } \\
\text { not } \\
\text { processed }\end{array}$}} & & \\
\hline & & & & & & & & $C_{d-p o l}$ & -1.21 & 0.52 & & & & \\
\hline$\sum_{16} \mathrm{PAH}$ & & & & & 600 & 047 & $\sum_{16} \mathrm{PAH}$ & $\tau$ & 3.00 & 0.52 & & & & \\
\hline$(\mathrm{ng} / \mathrm{l})$ & M3 & not & & & 0.90 & 0.41 & (ng/l) & $C_{d-p o l}$ & 5.42 & 0.63 & & & M4 & \\
\hline$\sum_{13} \mathrm{PAH}$ & releva & ht: $\rightarrow$ & Smal & mple: & 670 & 048 & $\sum_{13} \mathrm{PAH}$ & $\tau$ & 3.00 & 0.51 & & & $\underset{\rightarrow}{\mathrm{rele}}$ & \\
\hline$(\mathrm{ng} / \mathrm{l})$ & & & $\operatorname{not} \mathrm{p}$ & essed & 0.10 & 0.48 & (ng/l) & $C_{d-p o l}$ & 4.81 & 0.60 & & & & \\
\hline BDE-209 & 370 & 090 & & & 5.47 & 140 & As & $\tau$ & -4.74 & 0.20 & & & 3.85 & 0.58 \\
\hline (ng/l) & 3.70 & 0.99 & & & 5.47 & 1.40 & $(\mu \mathrm{g} / \mathrm{l})$ & $C_{d-p o l}$ & -0.48 & 0.17 & & & 0.78 & 0.37 \\
\hline$\sum_{9} \mathrm{PBDE}$ & 364 & 100 & & & 548 & 130 & $\mathrm{Ni}$ & $\tau$ & -3.49 & 0.46 & & & & \\
\hline$(\mathrm{ng} / \mathrm{l})$ & 3.64 & 1.00 & & & 5.48 & 1.39 & $(\mu \mathrm{g} / 1)$ & $C_{d-p o l}$ & 0.27 & 0.64 & & & poole & with \\
\hline & & & & & & & $\mathrm{Pb}$ & $\tau$ & -1.90 & 0.42 & & & & \\
\hline $\mathrm{BPA}(\mathrm{ng} / 1)$ & 600 & 062 & & & & & $(\mu \mathrm{g} / \mathrm{l})$ & $C_{d-p o l}$ & -0.66 & 0.63 & & oled & & \\
\hline BPA (ng/l) & & & & & & & $\mathrm{Sr}$ & $\tau$ & -1.91 & 0.43 & witl & Sucy & 6.23 & 0.73 \\
\hline & & & poo & with & poole & with & $(\mu \mathrm{g} / 1)$ & $C_{d-p o l}$ & 4.38 & 0.60 & & & -0.46 & 0.76 \\
\hline & & & & & & & $\mathrm{V}$ & $\tau$ & -3.28 & 0.33 & & & & \\
\hline$\sum \mathrm{OP}$ & 430 & 055 & & & & & $(\mu \mathrm{g} / \mathrm{l})$ & $C_{d-p o l}$ & 0.31 & 0.49 & & & poole & with \\
\hline (ng/l) & 4.39 & 0.55 & & & & & $\sum \mathrm{NP}$ & $\tau$ & 0.76 & 0.20 & & & & cy \\
\hline & & & & & & & (ng/l) & $C_{d-p o l}$ & 6.45 & 0.65 & & & & \\
\hline
\end{tabular}

